Review Article

\title{
Prevalence of Cardiovascular Disease and Associated Risk Factors among Adult Population in the Gulf Region: A Systematic Review
}

\author{
Najlaa Aljefree and Faruk Ahmed \\ Public Health, School of Medicine and Griffith Health Institute, Griffith University, Gold Coast Campus, QLD 4222, Australia \\ Correspondence should be addressed to Najlaa Aljefree; najlaa.aljefree@griffithuni.edu.au
}

Received 30 June 2014; Accepted 23 December 2014

Academic Editor: John Godleski

Copyright (C) 2015 N. Aljefree and F. Ahmed. This is an open access article distributed under the Creative Commons Attribution License, which permits unrestricted use, distribution, and reproduction in any medium, provided the original work is properly cited.

Background. CVD is a principal cause of mortality and disability globally. Objective. To analyse the epidemiological data on CHD, strokes, and the associated risk factors among adult population in the Gulf countries. Methods. A systematic review of published articles between 1990 and 2014 was conducted. Results. The analysis included 62 relevant studies. The prevalence of CHD was reported to be 5.5\% in Saudi Arabia. The annual incidence of strokes ranged from 27.6 to 57 per 100000 in the Gulf countries with ischaemic stroke being the most common subtype and hypertension and diabetes being the most common risk factors among stroke and ACS patients. The prevalence of overweight and obesity ranged from $31.2 \%$ to $43.3 \%$ and $22 \%$ to $34.1 \%$ in males and from $28 \%$ to $34.3 \%$ and $26.1 \%$ to $44 \%$ in females, respectively. In males, the prevalence of hypertension and diabetes ranged from $26.0 \%$ to $50.7 \%$ and $9.3 \%$ to $46.8 \%$, respectively; in females these ranged from $20.9 \%$ to $57.2 \%$ and $6 \%$ to $53.2 \%$, respectively. The prevalence of inactivity was from $24.3 \%$ to $93.9 \%$ and $56.7 \%$ to $98.1 \%$ in males and females, respectively. Relatively more males (13.4\% to $37.4 \%$ ) than females ( $0.5 \%$ to $20.7 \%)$ were current smokers. Available data indicate poor dietary habits with high consumption of snacks, fatty foods, sugar, and fast food. Conclusion. Effective preventative strategies and education programs are crucial in the Gulf region to reduce the risk of CVD mortality and morbidity in the coming years.

\section{Introduction}

Cardiovascular disease (CVD) is now recognized as the leading cause of death and disability worldwide [1]. The World Health Organization (WHO) estimated that in 2008, out of 17.3 million CVD deaths globally, heart attacks (myocardial infarction) and strokes were responsible for 7.3 and 6.2 million deaths, respectively [1]. According to the INTERHEART and INTERSTROKE studies, hypertension, diabetes, dyslipidaemia, obesity, smoking, physical activity, poor diet, and alcohol consumption are the most common risk factors for myocardial infarction (heart attack) and strokes worldwide $[2,3]$.

The Gulf Cooperation Council (GCC) is cooperation between Saudi Arabia, Bahrain, Oman, Qatar, the United Arab Emirates, and Kuwait. In 1981, the GCC was created to encourage investment and to adopt free trade between member states. This agreement also contributed to several fields including: education, culture, tourism, social opportunities, and health among the GCC members. The discovery of oil and other natural resources such as gas in the GCC countries including Saudi Arabia led to rapid development and economic growth [4]. Along with the rapid socioeconomic growth in the Gulf countries, there has been a change in lifestyle such as an increased consumption of poor quality foods and the adoption of a sedentary lifestyle [5], and as a consequence the rates of CVD and associated risk factors among the Gulf population have also increased; the rates sometimes exceed that of developed countries [5]. Furthermore, the number of deaths resulting from ischemic heart disease and hypertensive heart disease in the Middle East and North Africa region (including the GCC countries) was 294/100,000 and 115/100,000 respectively. Also, the number of disability-adjusted life years (DALYs) resulting from 


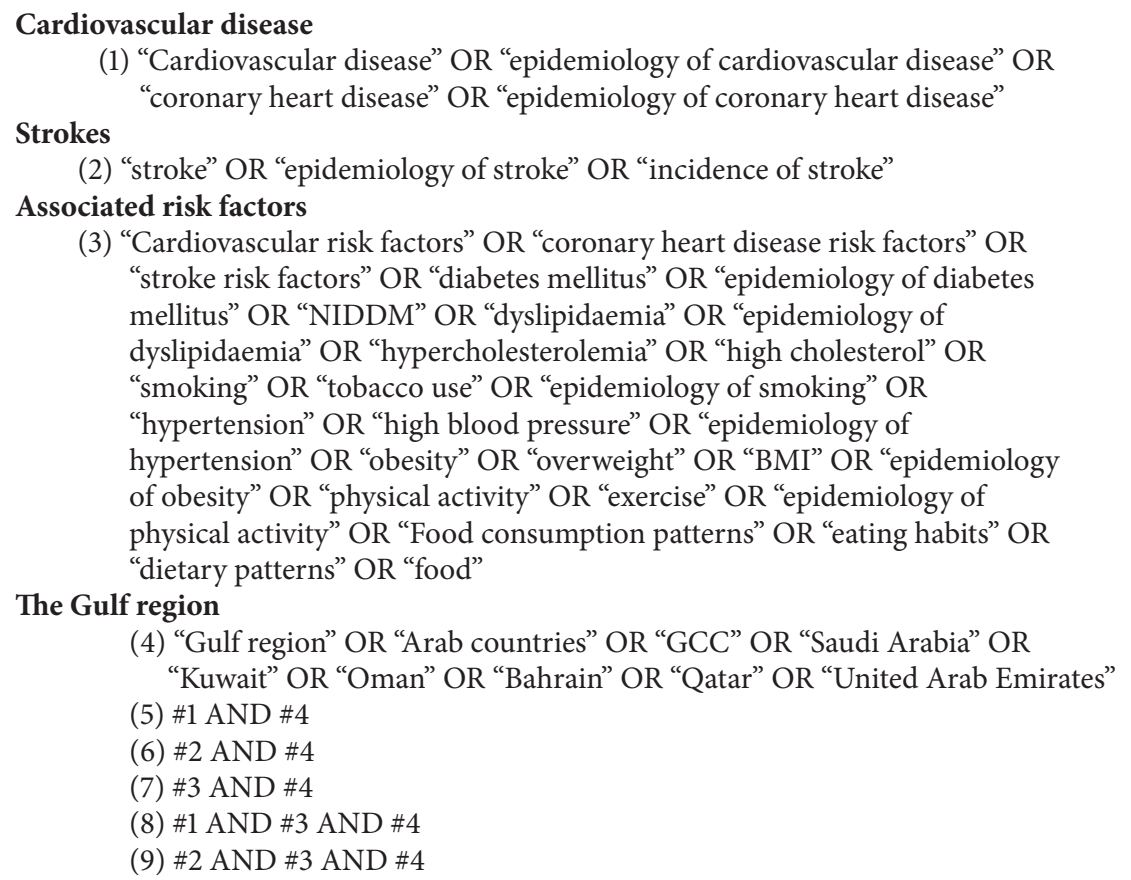

Box 1: Selected search terms.

ischemic and hypertensive heart disease is 3702/100,000 and $1389 / 100,000$, respectively, in the same region [6]. The WHO estimated the total number of noncommunicable diseases resulting in death in the GCC states in 2008. CVD was estimated to account almost half of the deaths in Oman and Kuwait, $49 \%$ and $46 \%$, respectively. The rate of CVD deaths was also high in Saudi Arabia, the UAE, Bahrain, and Qatar $42 \%, 38 \%, 32 \%$, and $23 \%$, respectively [7]. Although some systematic reviews on the prevalence of CVD and/or CVD risk factors in the Middle East region have been published $[8,9]$, these reviews were limited to either CVD risk factors only [8], or specific gender [9]. To our knowledge, this is the first systematic review that provides a comprehensive analysis on the prevalence of $\mathrm{CHD}$, strokes, and associated risk factors in the Arabic Gulf countries. The aim of this paper was to review the epidemiology of $\mathrm{CHD}$, strokes, and the related risk factors among the adult population in the GCC.

\section{Methods}

2.1. Data Sources. An extensive literature search was conducted on the prevalence of CHD and incidence of strokes and the burden of associated risk factors to identify articles or reports published between 1990 and 2014 using ProQuest Public Health, MEDLINE, PubMed, Google Scholar, and World Health Organization (WHO) website. A manual search of reference lists of original studies was searched. In addition, checking the review articles, contacting authors, the official website of the Gulf Heart Association were also searched http://www.gulfheart.org/ and the section labelled
"GHA studies" was specifically scanned. The search terms used were shown in Box 1 .

2.2. Study Selection. A total of 7800 articles were identified in initial search. The titles and abstracts of all articles of potential interest were reviewed for inclusion and exclusion of studies. The criteria for selected studies aimed to include studies that indicated the prevalence of CHD and/or stroke and/or at least one of the associated risk factors: diabetes, hypertension, obesity, dyslipidaemia, dietary habits, smoking, and physical activity. All the included studies were required to only include individuals over 18. The CHD and stroke studies were not restricted by sample size due to the limited numbers of these studies in the GCC countries. However, all the included studies that examined the burden of the risk factors were restricted with a sample size that exceeded 500 except for diet studies. All selected studies were required to relate to at least one of the GCC populations. Only studies published in English and where full manuscripts were included. Studies were published in abstract form and those on congenital heart disease or other CVDs were excluded. A total of 190 full-text papers were identified and further reviewed. Finally, 62 articles including two articles by contacting authors directly were included in this review. Figure 1 summarizes the selection process of the reviewed studies.

2.3. Data Abstraction and Quality Assessment. Data extracted for each study included first author and publication year, sample size, demographic characteristics, the country of study, place of study, study objectives, year(s) of survey, response rate, study methods, the definition of $\mathrm{CHD}$ and/or 


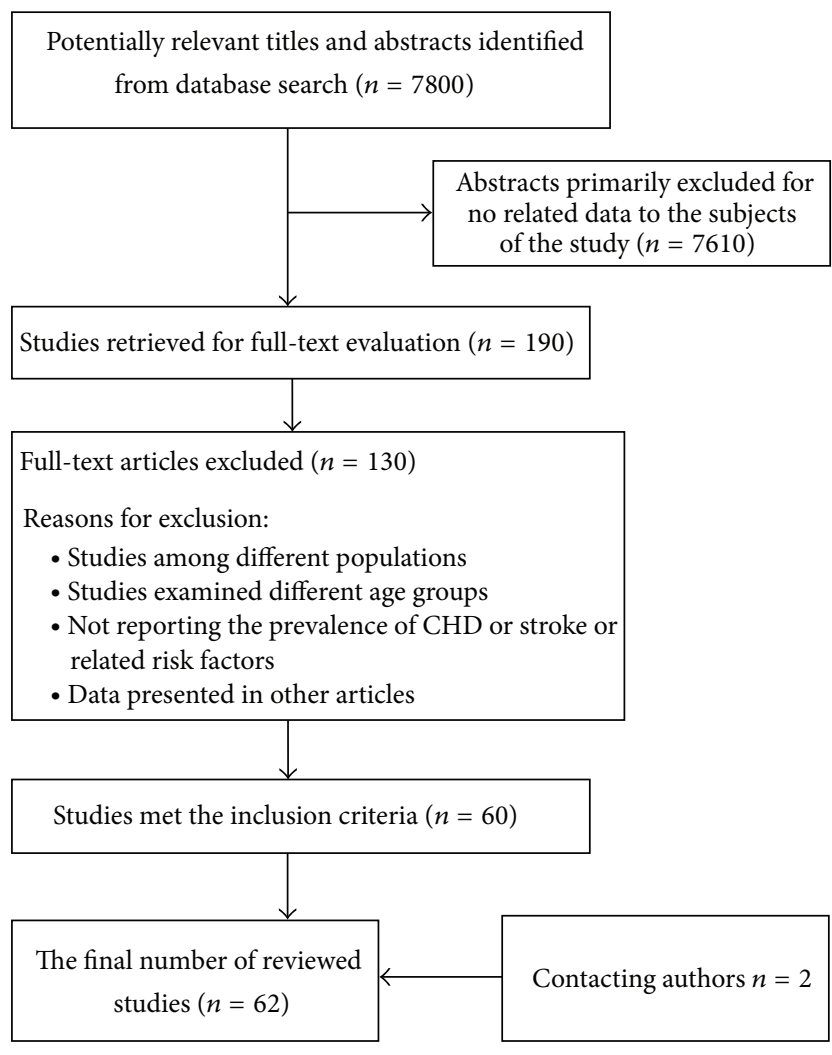

FIgURE 1: Study selection process.

stroke and/or associated risk factors, and the prevalence of $\mathrm{CHD}$ and/or stroke and/or associated risk factors. The quality of selected studies was assessed according to the Centre for Reviews and Dissemination guidelines [10]. Since there are few papers that addressed the study questions, no studies were excluded for their qualities. The quality assessment checklist of the included studies in the systematic review is shown in the far-right column of Tables 1 and 2.

2.4. Data Synthesis. A narrative synthesis was performed to identify the study questions. It included describing all the included papers, summarising the findings of the data extracted from each study, and exploring the relationships between the results of the different studies.

\section{Results}

Of the 62 articles that are reviewed in the present study, 13 were published in the 1990s, another 40 in the 2000s, and 9 in the last four years. Of the included studies, 4 reported data on CHD, 12 on stroke, and 46 on the prevalence of the associated risk factors. Further, of these 62 selected studies, 22 were carried out among Saudi, 8 in Bahraini, 10 in Kuwaiti, 5 in Omani, 6 in Qatari, and 8 in the UAE populations, and 3 were carried out in multiple GCC countries. Regarding the study design; 48 studies were cross-sectional, 7 were retrospective, and 7 were prospective observational studies. Seven studies looked at employees, 4 at university and college students,
8 at primary health care attendants, 14 at CHD and stroke patients, and 29 at the general population. The sample size in CHD and stroke studies ranged from 62 to 23,227 and in the burden of risk factors studies it ranged from 227 to 195,874. Response rates ranged from $59 \%$ to $99.8 \%$. The summary of the included articles on CHD and strokes is shown in Table 1, whereas the summary of included articles on the burden of associated risk factors is shown in Table 2.

3.1. CHD and Strokes in the GCC Region. Overall, there is a lack of information on CHD and strokes in Arabic Gulf countries. The only nationally representative study conducted in Saudi Arabia reported the crude prevalence of CHD of $5.5 \%$ among the Saudi population [11]. This survey reported a higher prevalence of $\mathrm{CHD}$ in males $(6.6 \%)$ compared to females (4.4\%) and in urban Saudis (6.2\%) than rural Saudis (4.0\%). Further, the prevalence of CHD increased with age from $3.9 \%$ in $30-39$-year olds to $9.3 \%$ in the $60-70$-year olds [11].

The Gulf Registry of Acute Coronary Events (Gulf RACE), a project of Gulf Heart Association aimed to describe the characteristics, in-hospital outcomes, and associated risk factors of the acute coronary syndrome patients (ACS) and recruited patients from 64 hospitals in Bahrain, Oman, Qatar, Kuwait, the UAE, and Yemen [12, 13]. The Gulf RACE study reported ACS was more prevalent in male (74\%) than female (24\%) patients [12]. It also reported a high prevalence of diabetes (40\%), hypertension (49\%), dyslipidaemia (32\%), smoking (38\%), and obesity (27\%) among ACS patients in the five Gulf countries [13]. The highest rates of the risk factors were in Bahrain and Kuwait, except for smoking, which has the highest rates in the UAE and Kuwait [13]. The prevalence of CVD risk factors was higher in females than males, including diabetes (55\% versus 36\%), hypertension (70\% versus $43 \%$ ), and dyslipidaemia (44\% versus $28 \%$ ), respectively [12]. Significantly more males (47\%) than females (5\%) were current smokers [13].

Similarly, the Saudi Project for Assessment of Coronary Events (SPACE) registry reported the characteristics and prevalence of risk factors among ACS patients in Saudi Arabia [14]. The SPACE registry reported that ACS was more frequent in males (77\%) than females (23\%) [14]. Ischemic heart disease was present in $32 \%$ of the study population. The study also reported diabetes to be the most common risk factor for CHD (56\%) followed by hypertension (48\%), being a current smoker (39\%), and hyperlipidaemia (31\%) [14].

The available data on strokes and the associated risk factors in the GCC were derived mostly from retrospective hospital-based studies but no population-based studies. The data on strokes and associated risk factors was reported in 12 studies: 4 in Saudi Arabia [15-18], 1 in Bahrain [19], 3 in Kuwait [20-22], 3 in Qatar [23-25], and 1 from multiple GCC countries [26].

Five studies reported the incidence of stroke in Saudi Arabia, Kuwait, Qatar and Bahrain [15, 17, 19, 20, 25]. The incidence of stroke ranged from 27.6 per 100000 in Kuwait to 57 per 100000 in Bahrain $[15,17,19,20,25]$. Further, the most common type of stroke in the region was ischemic 


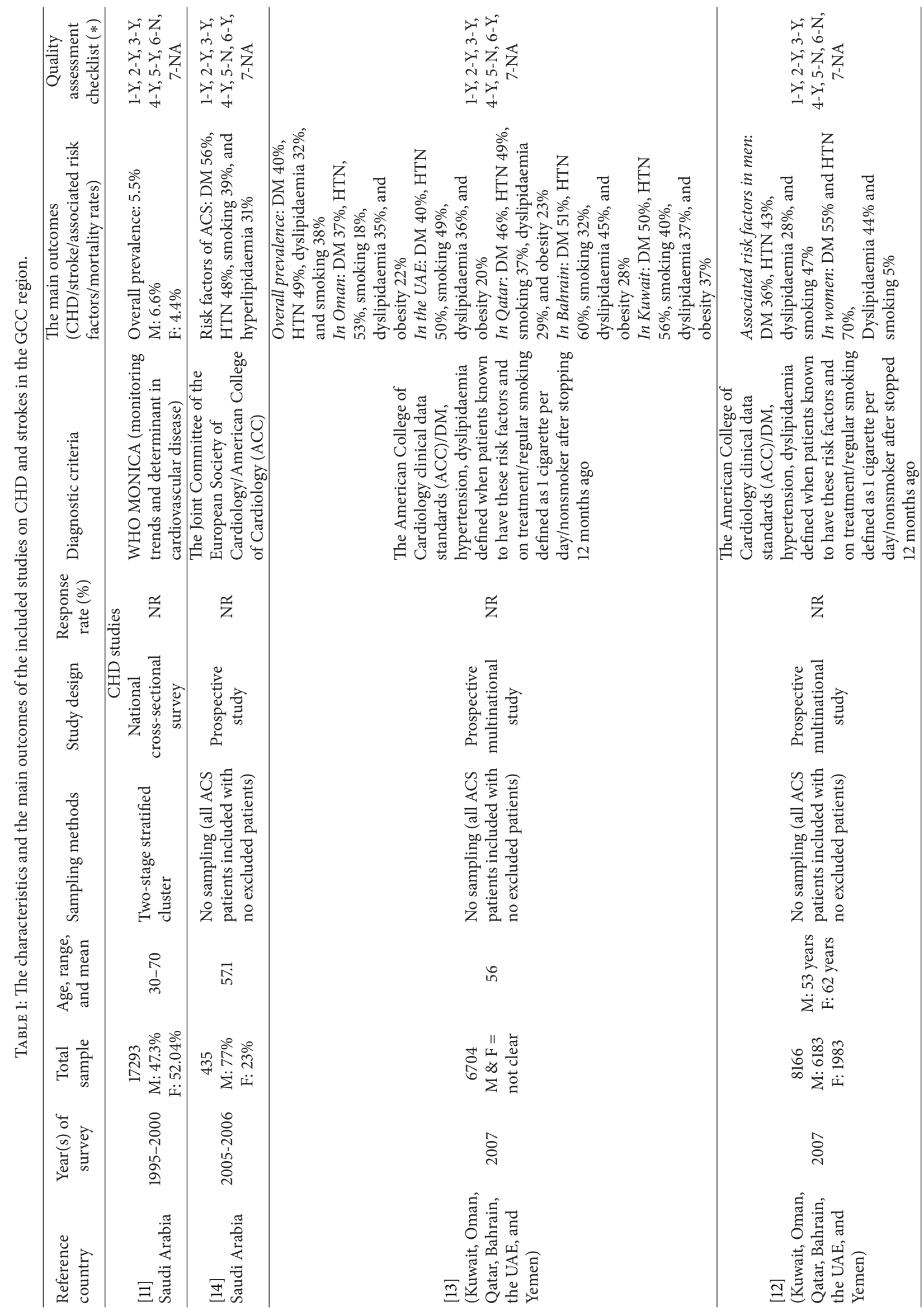




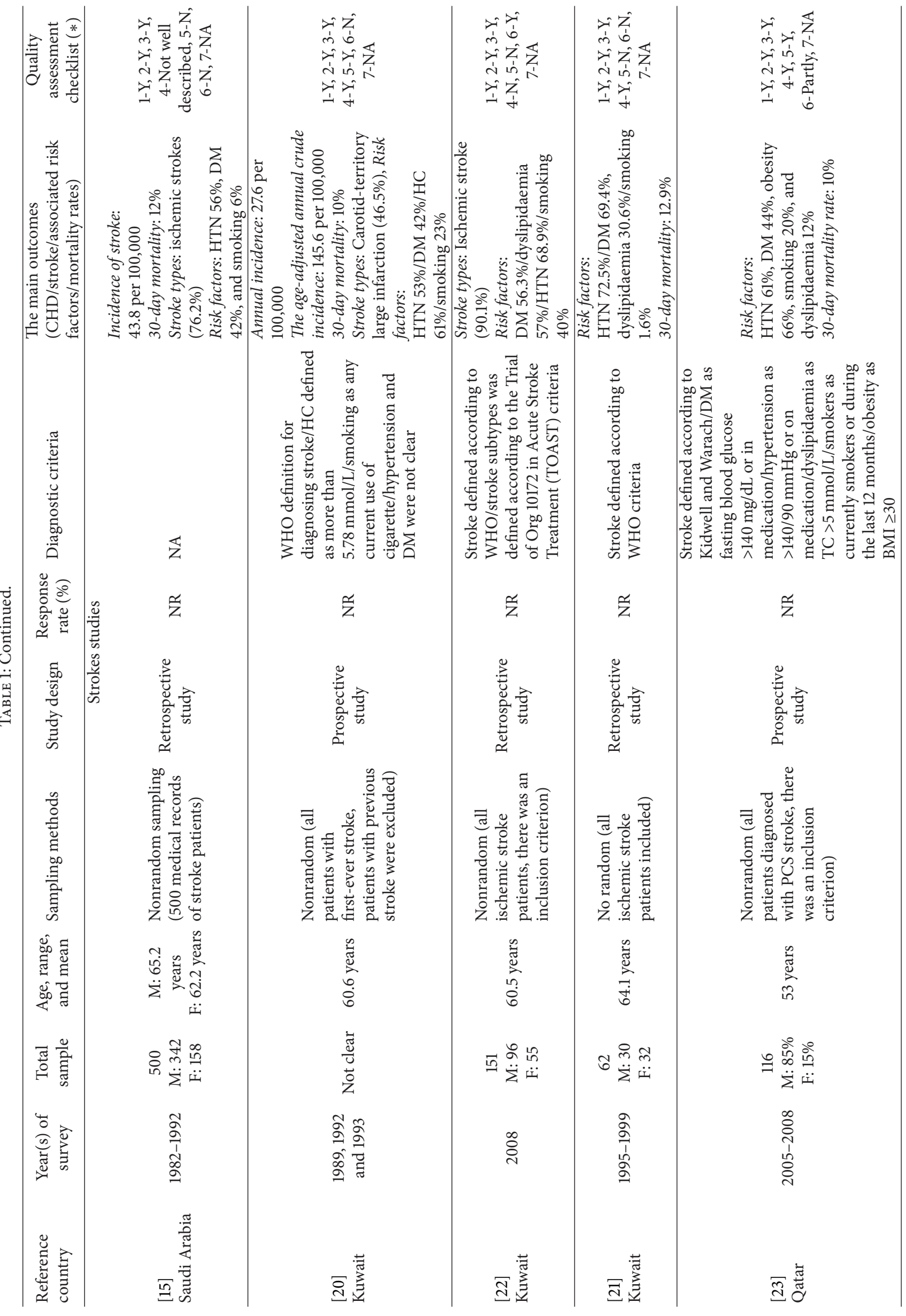




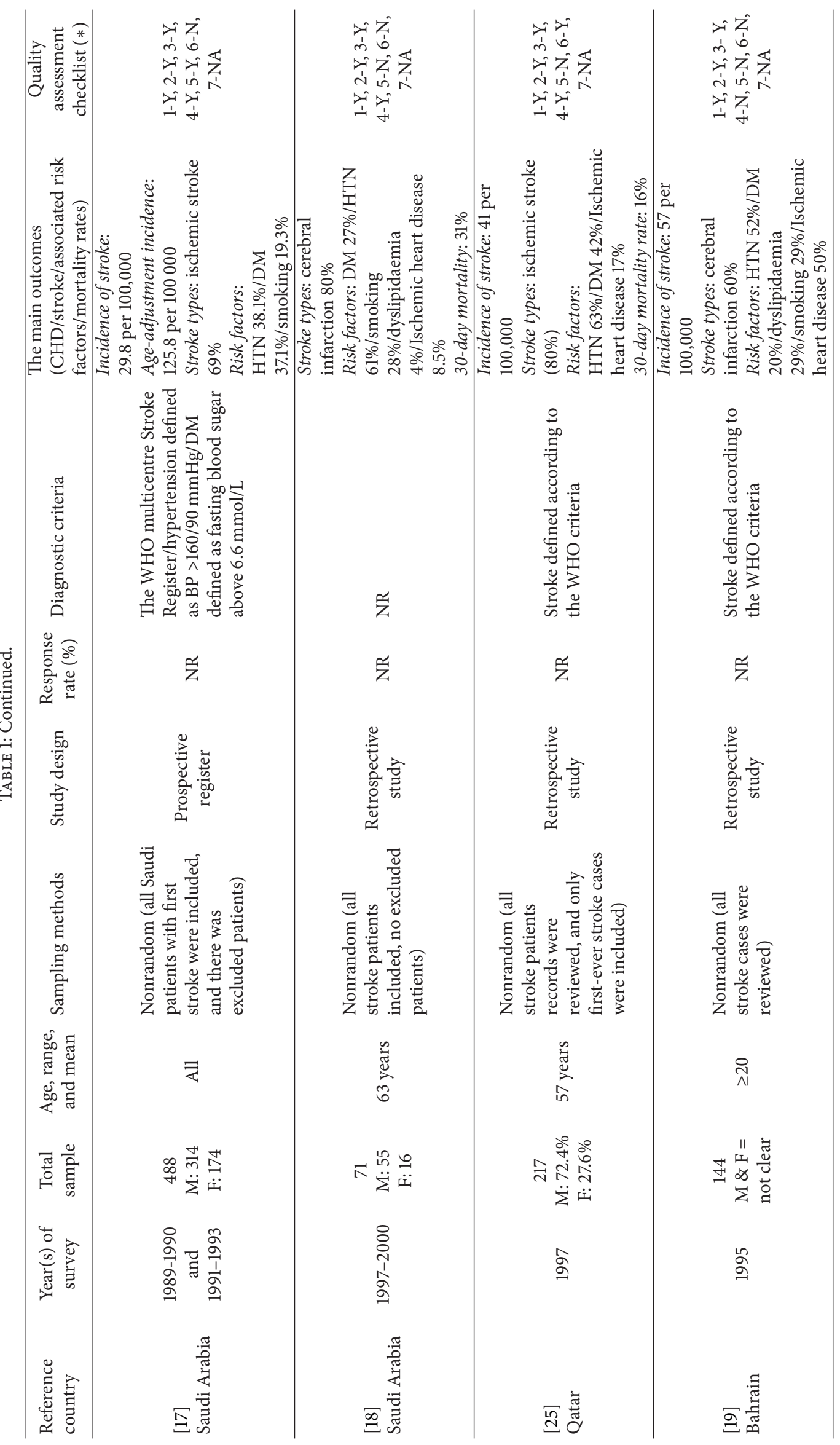




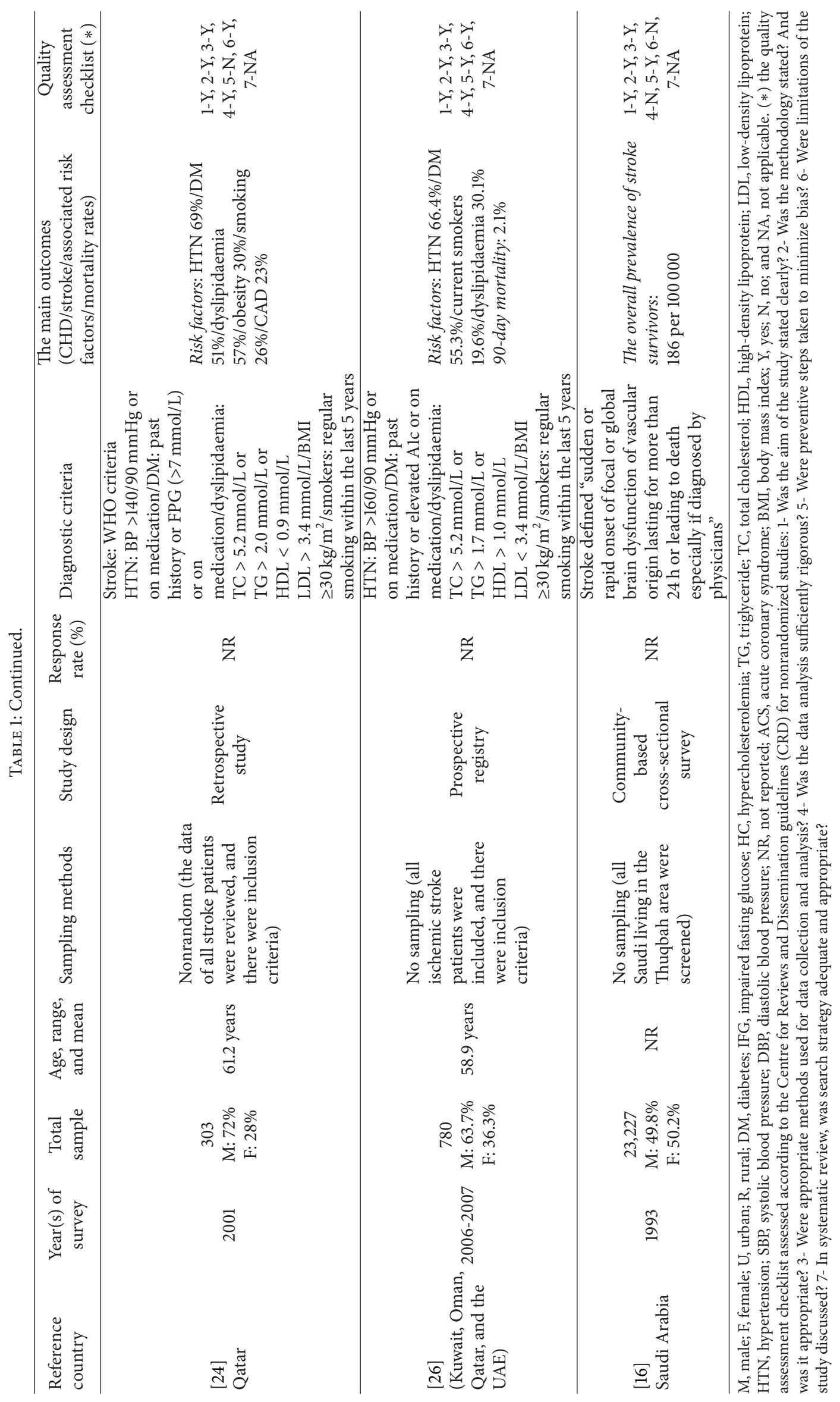




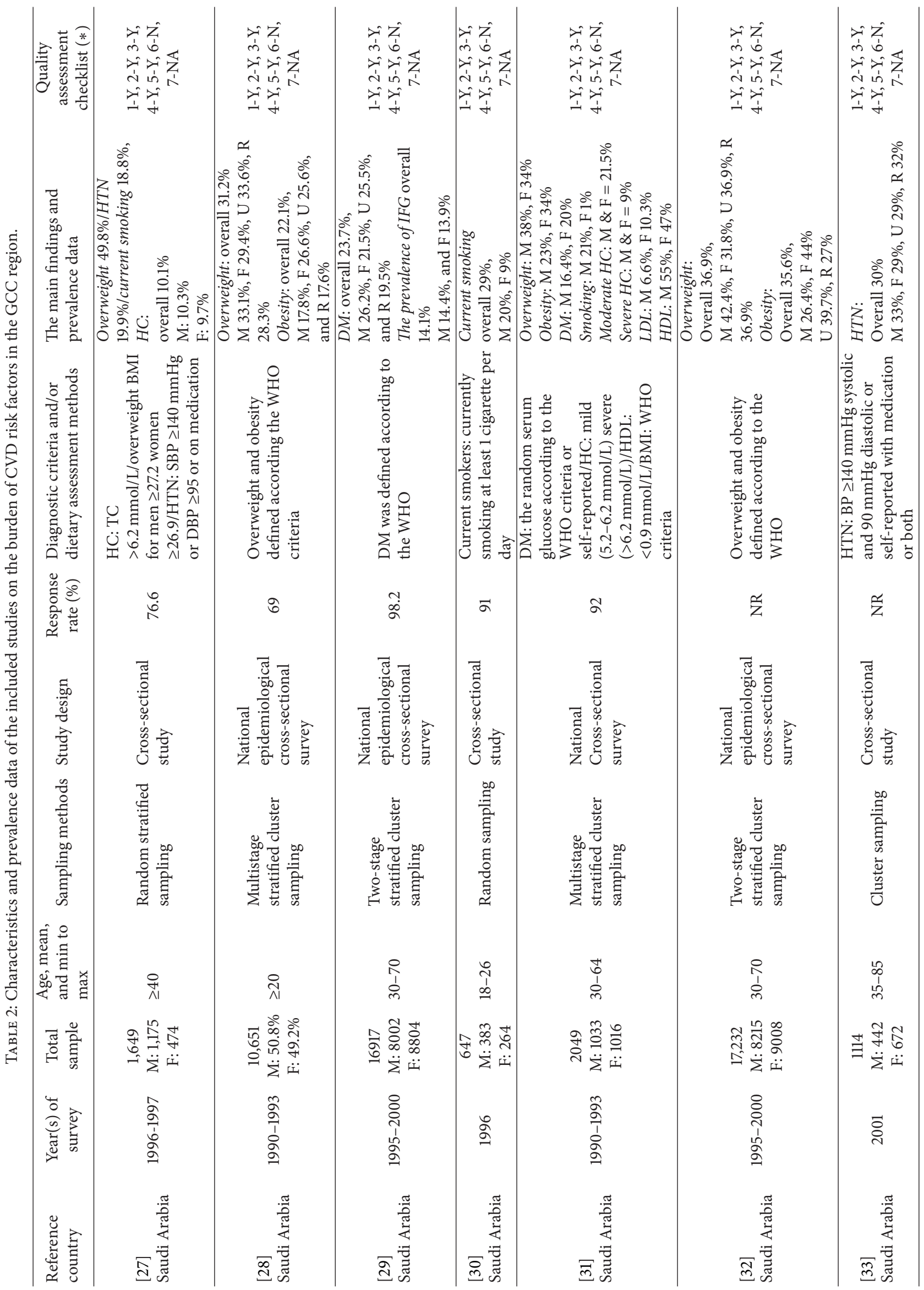




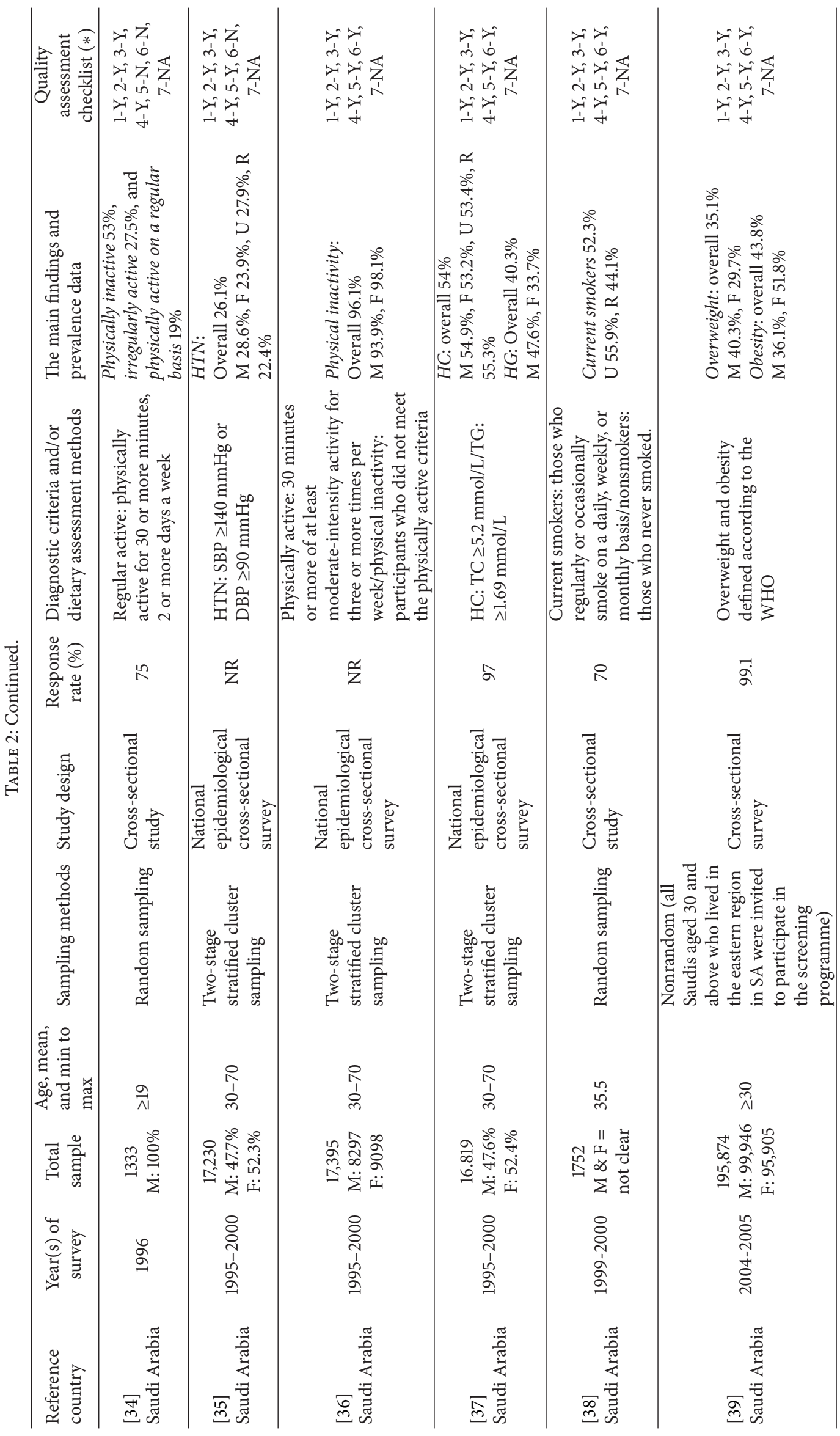




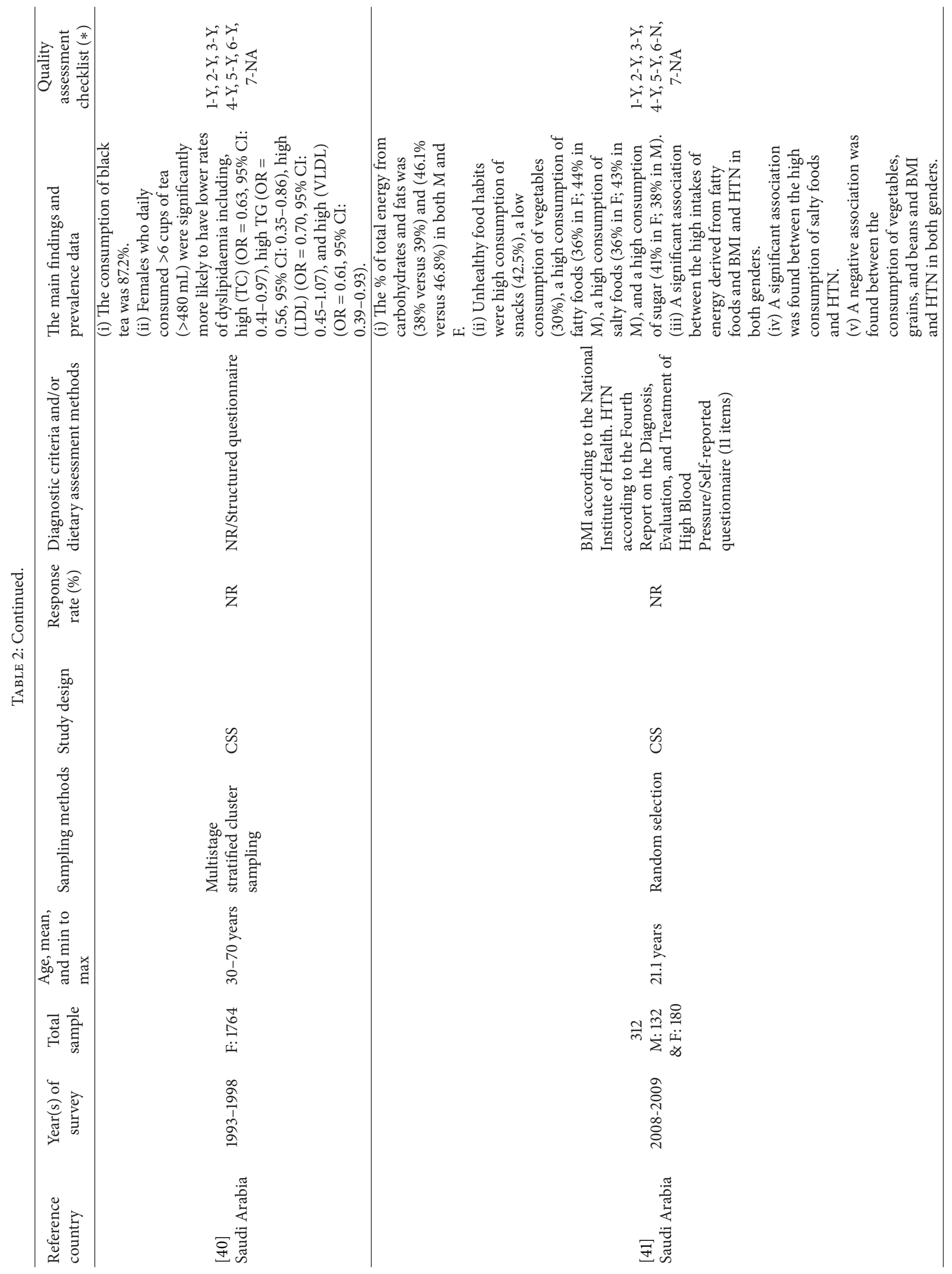




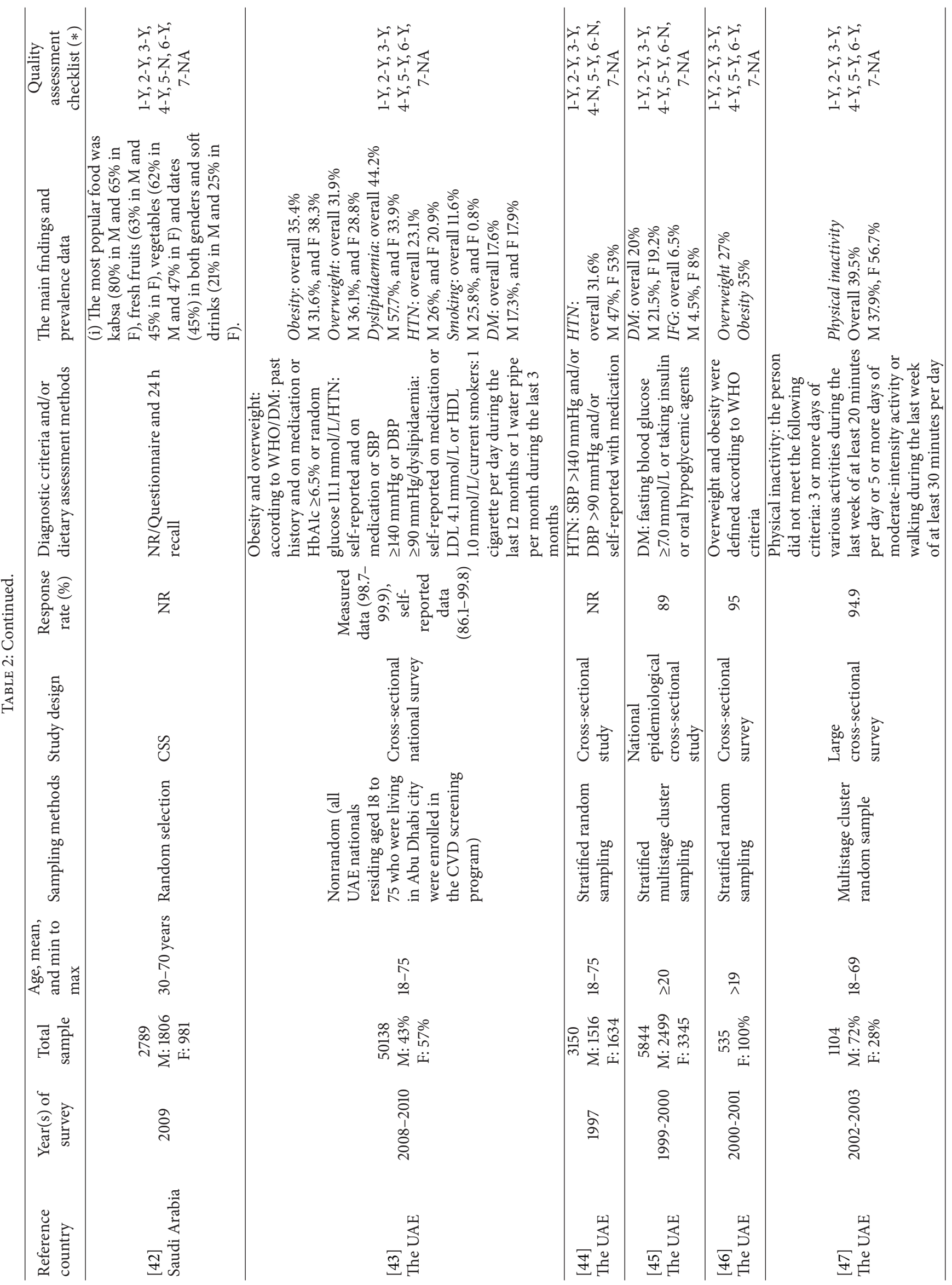




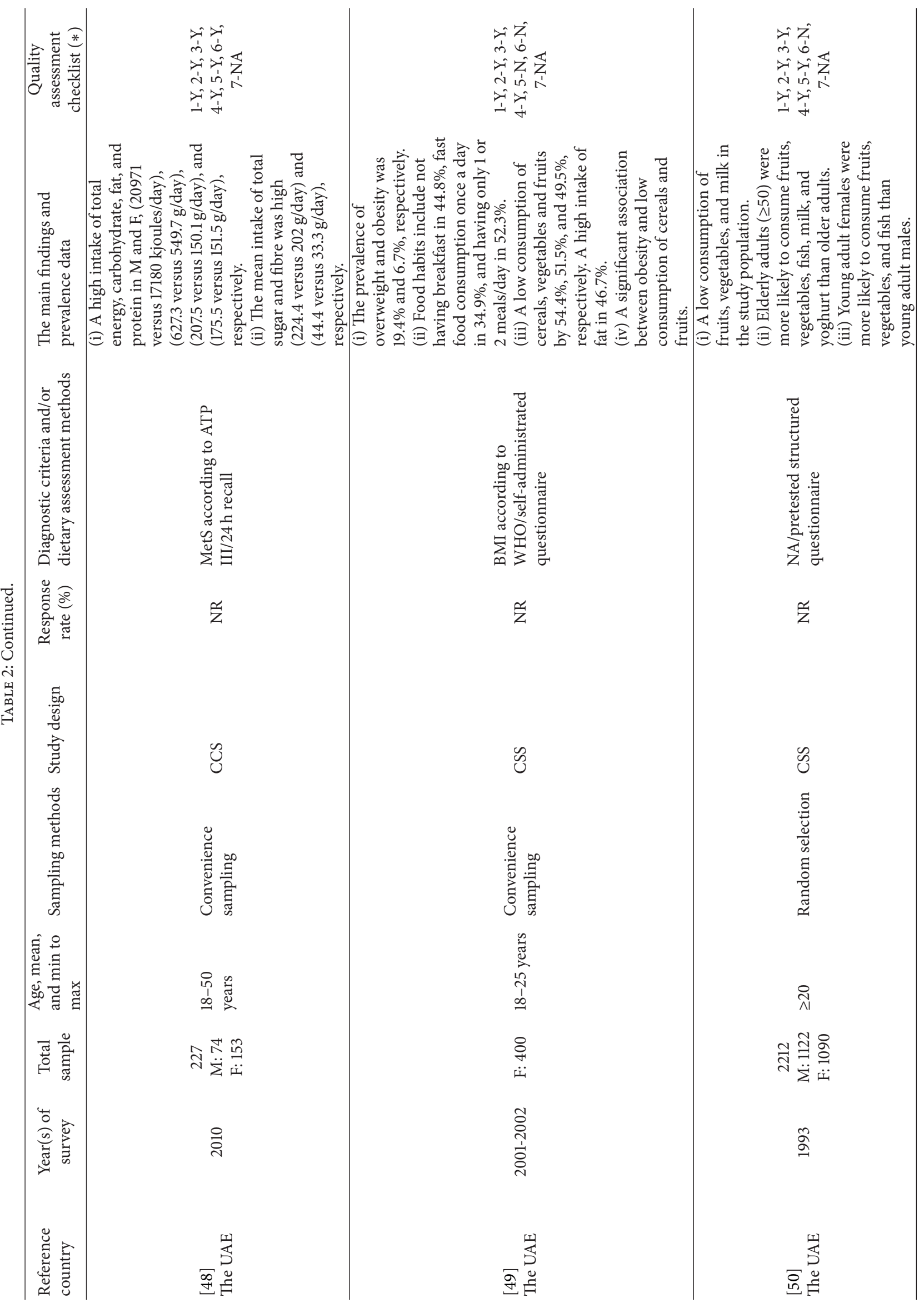




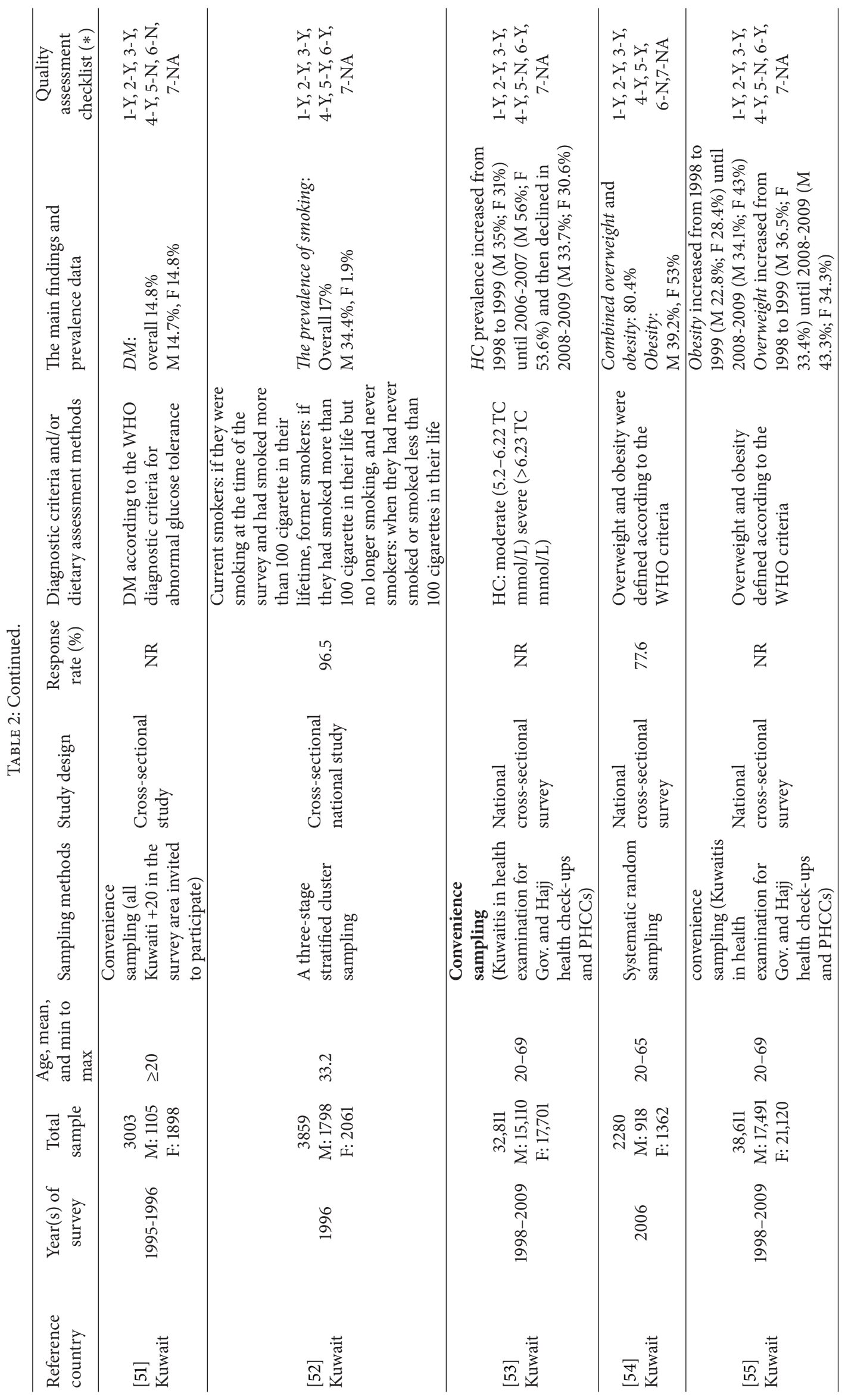




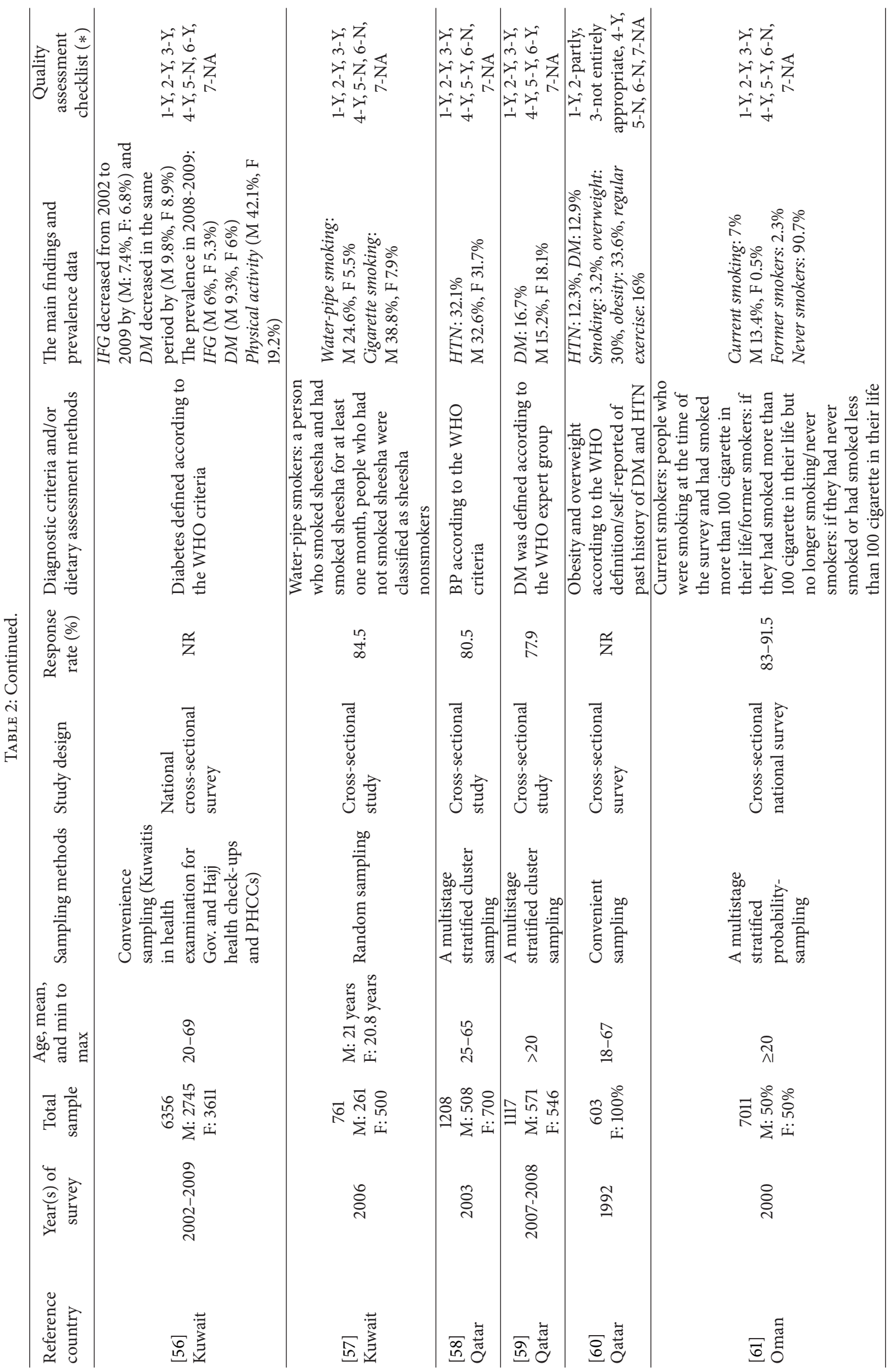




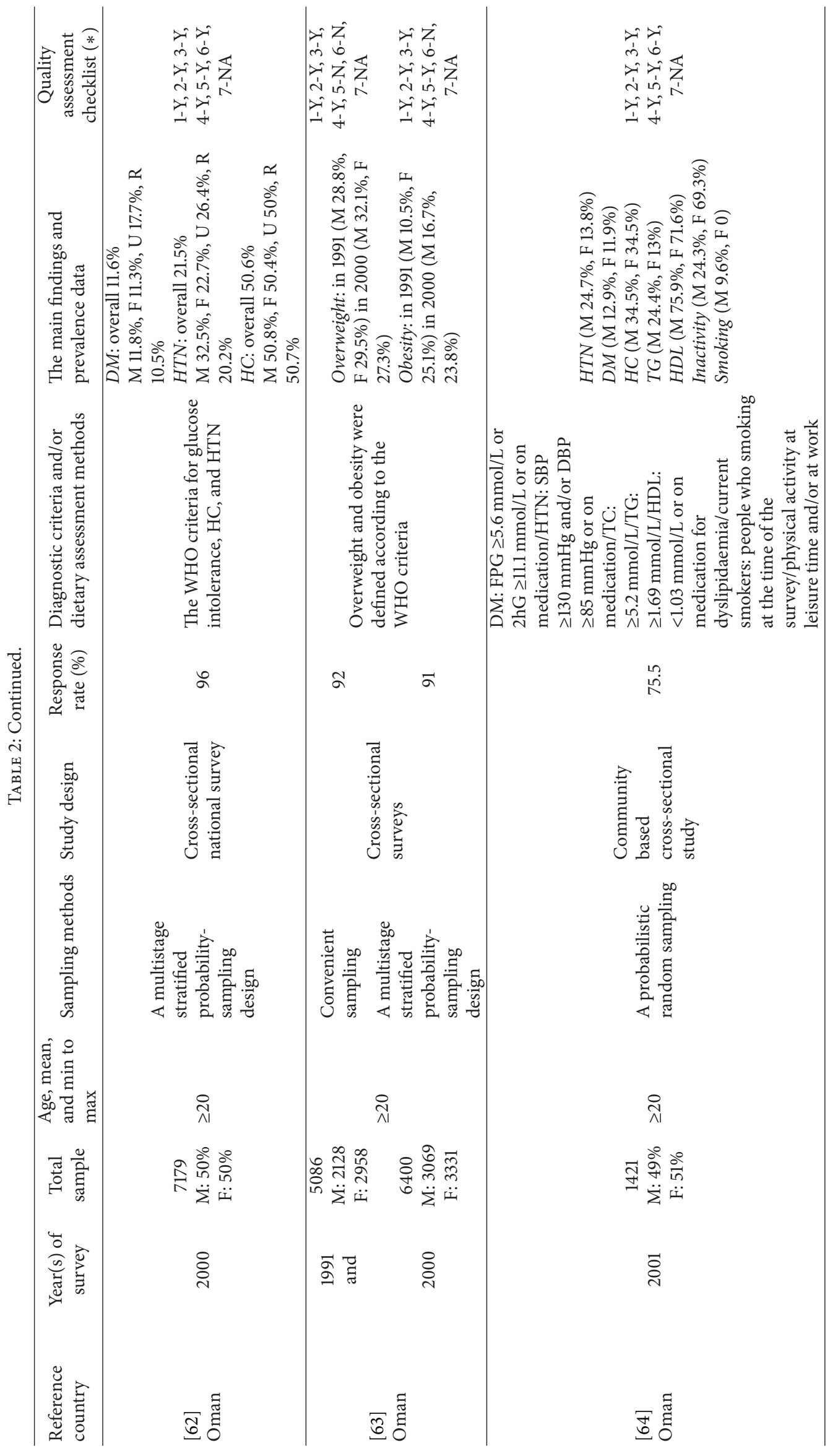




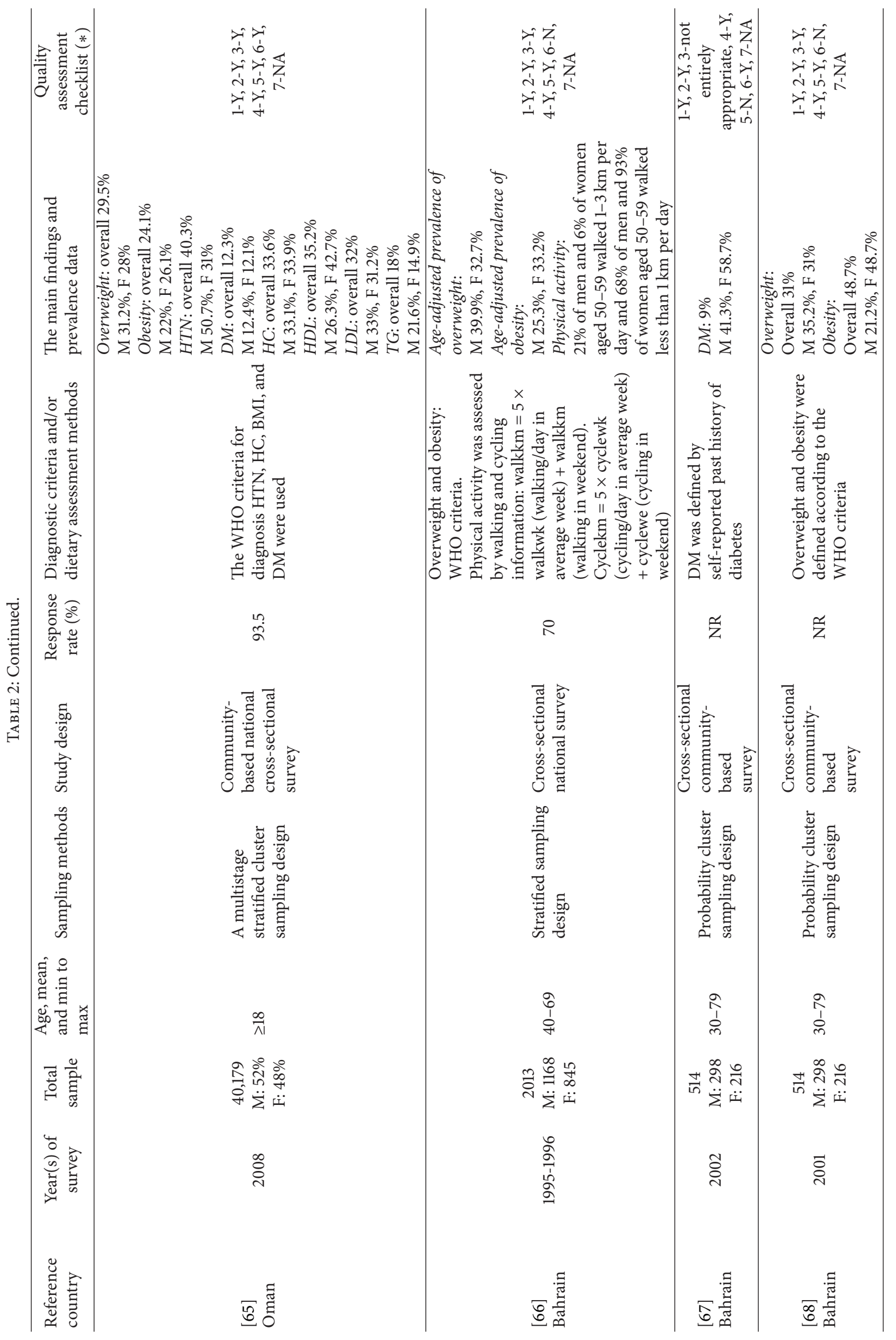




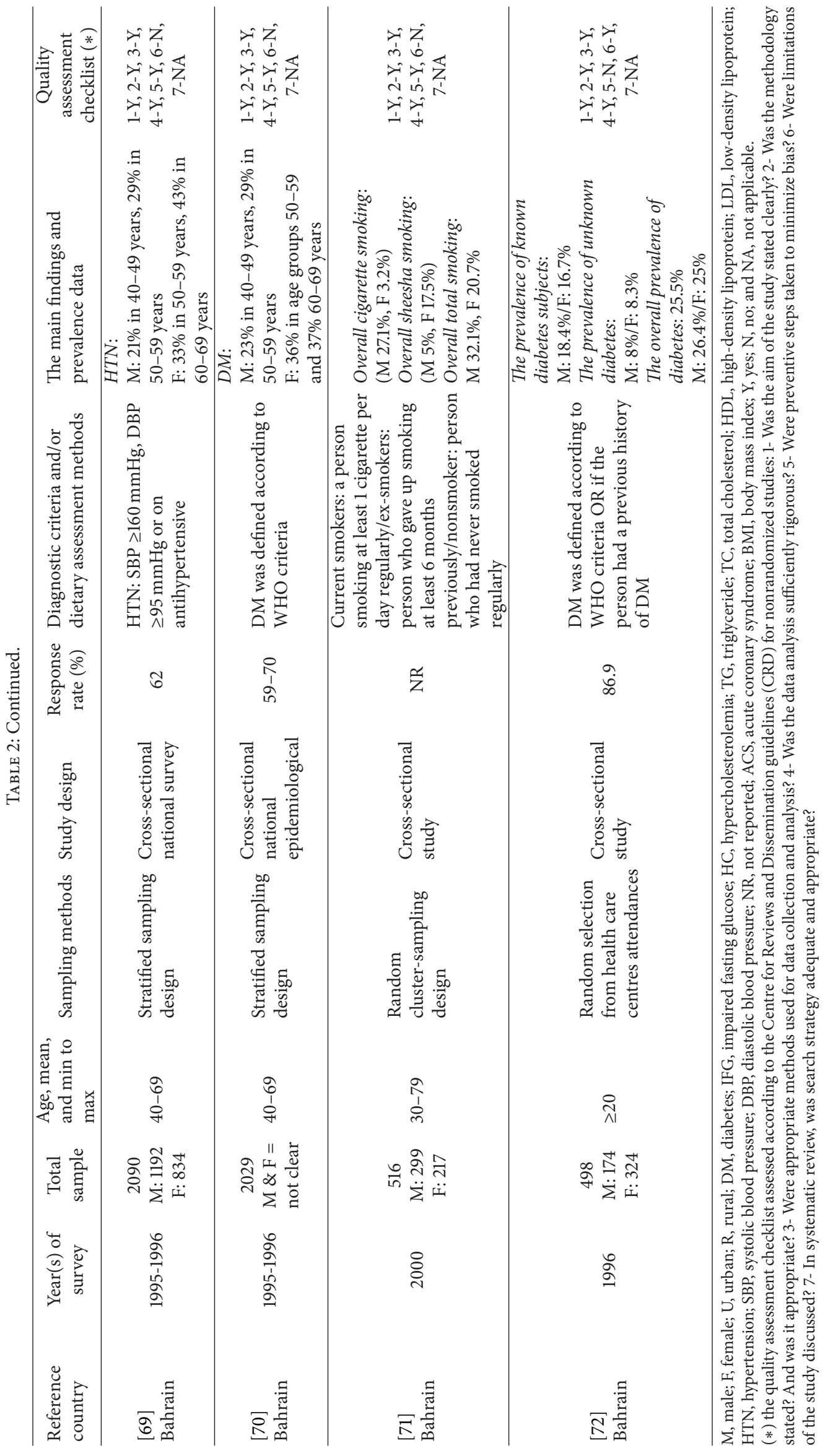


ranging from 69 to $90.1 \%[15,17,22,25]$. There was no data available on the incidence of strokes in Oman and the UAE. Only one study in Saudi Arabia reported on the number of stroke survivors as 186/100,000 [16]. Further, in the majority of stroke studies, the incidence of strokes was higher in males than females across all age groups and it increased with age $[15,17-20,25]$, although there was still relatively high stroke incidence in younger age groups ( $\leq 45$ years) in the GCC region $[15,17,19,23]$. Across all stroke studies, hypertension (38.1-72.5\%) was the most common risk factor, followed by diabetes (20-69.4\%) for stroke patients [15, 1726]. Dyslipidemia was reported in $4-61 \%$ of stroke patients $[18-24,26]$. Smoking was reported in $1.6-40 \%$ of stroke patients in the GCC $[15,17-24,26]$.

3.2. The Burden of the CHD and Stroke Risk Factors in the GCC Region. The risk factors for CHD and stroke can be categorized into two groups: metabolic risk factors (obesity, hypertension, diabetes, and dyslipidaemia) and behavioural risk factors (diet, smoking, and physical activity). In this section, the burden of various risk factors among healthy population in the GCC states is described.

3.2.1. Overweight and Obesity. Prevalence of overweight and obesity has been reported in 13 studies: 4 in Saudi Arabia [28, 31, 32, 39], 2 in Bahrain [66, 68], 2 in Kuwait [54, 55], 2 in Oman [63, 65], 1 in Qatar [60], and 2 in the UAE [43, 46].

Based on the available national representative studies, the prevalence of overweight in males and females in the GCC region ranged from $28.8 \%$ to $42.4 \%$ and from $27.3 \%$ to $32.7 \%$, respectively, while the prevalence of obesity in males ranged from $10.5 \%$ to $39.2 \%$ and in females ranged from $18.2 \%$ to $53 \%$. The prevalence of overweight and obesity increased with age with the highest level in the middle age groups (30-39 and $40-49$ years) $[28,31,32,39,43,46,54,55,60,63,65,66,68]$. The obesity rates in urban areas were higher than in rural areas $[28,31,32,63]$. In general, the prevalence of overweight and obesity is remarkably high in the GCC states and Oman reported the lowest rates of obesity within the region.

3.2.2. Hypertension. The prevalence of hypertension was reported in 10 studies: 3 in Saudi Arabia [27, 33, 35], 1 in Bahrain [69], 2 in Oman [62, 65], 2 in Qatar [58, 60], and 2 in the UAE $[43,44]$.

The rate of hypertension in the GCC states ranged from $26 \%$ to $50.7 \%$ in males and from $20.9 \%$ to $31.7 \%$ in females $[33,35,43,44,58,62,65,69]$. Across all studies, the prevalence of hypertension considerably increased with age with the highest rates in the $45-65$ age groups. The prevalence of hypertension in Saudi Arabia was lower than Oman, Bahrain, and Qatar but close to the UAE. The lower rate of hypertension in Saudi Arabia may not be true reflection of the situation as the reported study was relatively old [35].

3.2.3. Diabetes Mellitus. The rates of diabetes mellitus in the GCC countries were addressed in 13 studies: 2 in Saudi Arabia [29, 31], 3 in Bahrain [67, 70, 72], 2 in Kuwait [51, 56], 2 in Oman [62, 65], 2 in Qatar [59, 60], and 2 in the UAE [43, 45].
The overall prevalence of diabetes ranged from $6 \%$ to $23.7 \%$ in the GCC. Three studies showed higher diabetes rates among females $[31,59,67]$, while three studies indicated the opposite $[29,45,56]$. Four studies showed almost no difference in the prevalence of diabetes between genders $[43,51,62,65]$. The prevalence of diabetes rose proportionally with age and reached the highest rates in both sexes among those aged 55-64 years and over $[29,31,43,45,51,56$, $59,62,65,67]$. It was also considerably higher among the urban population $[29,62]$. Overall, the available data on the prevalence of diabetes in this region indicated that Saudi Arabia, Bahrain, and the UAE have the highest rates of diabetes compared to the other Gulf countries especially Kuwait, where the rates of diabetes were relatively lower; however this might be due to the underestimation of the actual prevalence in one Kuwaiti study as it excluded diabetic subjects on medication [56].

3.2.4. Dyslipidaemia. The prevalence of dyslipidaemia was reported in 7 studies: 3 in Saudi Arabia [27, 31, 37], 1 in Kuwait [53], 2 in Oman [62, 65], and 1 in the UAE [43]. There was no consistent definition of dyslipidaemia within the region. The majority of the dyslipidaemia studies reported the prevalence rate based on total cholesterol and triglycerides levels.

Overall, dyslipidaemia levels were higher in males than females and increased with age gradually up to the age group of 50-59 when it became stable in some studies and slightly declined in others. The prevalence of hypercholesterolemia (HC) ranged from $17 \%$ to $54.9 \%$ in males and from $9 \%$ to $53.2 \%$ in females $[27,31,37,53,62,65]$. There was no difference in HC between urban and rural residents [37, 62]. However, one study in Saudi Arabia showed higher rates of hypertriglyceridemia in the urban population (43.2\%) than rural population (34.1\%) [37]. Based on the available data on dyslipidaemia within the region, $\mathrm{HC}(\geq 5.2 \mathrm{mmol} / \mathrm{L})$ was more prevalent in Saudi Arabia. The variation in definitions used in dyslipidaemia studies and the limited data in the GCC make it difficult to accurately compare between countries; however the levels of blood lipids appeared to be high in the Gulf region.

3.2.5. Diet. Six studies carried out in Saudi Arabia [40-42] and UAE [48-50] have determined the eating habits among adult population in these countries.

The dietary patterns presented in these studies are mainly characterized by a high consumption of snacks, fatty food, salty food, and sugar. A study in Saudi Arabia reported that more than half of the study population was consuming a high amount of snacks and fatty and salty foods in daily basis [41]. Similarly, a high consumption of sugar and fast food was reported in the UAE $[48,49]$. Further, a low consumption of fruits, vegetable, and cereals was reported in several studies $[41,49,50]$. One study showed a high intake of fruits, vegetables, and dates [42]. The findings from these surveys also demonstrated a high intake of total energy, fats, and protein [41, 48]. A Saudi survey showed a high proportion of total energy derived from fat and carbohydrates (38\% versus $39 \%$ ) and ( $46.1 \%$ versus $46.8 \%)$ in both males 
and females, respectively [41]. Some of the popular unhealthy food habits reported were not having breakfast, consuming less than two meals per day, and a high consumption of fast food meals [41, 49]. A number of studies have examined the association between some food items and CVD risk factors $[40,41,49]$. One study showed an inverse association between consumption of black tea and serum lipids [40], while another study reported a significant association of high intake of energy derived from fatty foods with BMI and hypertension in both genders [41]. Further, low consumption of cereals and fruits was found to be associated with obesity [49].

3.2.6. Smoking. The prevalence of smoking in the Gulf region was addressed in 9 studies: 3 in Saudi Arabia [27, 30, 38], 1 in Bahrain [71], 2 in Kuwait [52, 57], 1 in Oman [61], 1 in Qatar [60], and 1 in the UAE [43].

The rates of cigarette smoking in the GCC ranged from $13.4 \%$ to $37.4 \%$ in males and from $0.5 \%$ to $20.7 \%$ in females. Furthermore, the prevalence of smoking fluctuated from age group to age group. It was more common in males at younger ages (18-25 years); however some studies reported a high prevalence in the older age group (40-59 years). In females, the highest rates of smoking were in the older age group (4049 years) [30, 43, 52, 57, 61, 71]. One study in Saudi Arabia reported higher rates of cigarette smoking in urban than rural subjects [38]. Overall, the prevalence of smoking was higher in Saudi Arabia, Kuwait, the UAE, and Bahrain in comparison to Oman.

3.2.7. Physical Activity. The prevalence of physical activity in the GCC countries was presented in 7 studies: 2 in Saudi Arabia [34, 36], 1 in Bahrain [66], 1 in Kuwait [56], 1 in Oman [64], 1 in Qatar [60], and 1 in the UAE [47].

The prevalence of inactivity was found to be significantly higher among the younger population in the region, and across all age groups physical inactivity was higher in females than males. The rates of inactivity ranged from $24.3 \%$ to $93.9 \%$ in males and from $50 \%$ to $98.1 \%$ in females in the GCC $[36,47,60,64,66]$. In general, the rates of physical inactivity were considerably high in the GCC region especially Saudi Arabia.

\section{Discussion}

This review revealed that, in the GCC region, there is a lack of information on the prevalence of CHD with only exception in Saudi Arabia where one national survey reported 5.5\% prevalence of CHD [11], which is lower than the prevalence rate reported in Egypt 8.3\% [73], while it is higher than in India (3\%), China (2\%), and Europe (5\%) $[74,75]$. However, it is important to note that the Saudi report is relatively old and may not reflect the current situation. The rates of ACS and associated risk factors appeared to be very similar in Saudi Arabia (SPACE report) and other Gulf states (Gulf RACE report) except for diabetes, which is more prevalent in Saudi Arabia. However, the SPACE registry results came from phase 1 (pilot study) and thus based on smaller sample size compared to that of Gulf RACE $[13,14]$.

In contrast to other ACS registries around the world, the prevalence rates of diabetes and current smoking are higher in the Gulf region, while a higher prevalence of hypertension and dyslipidaemia is observed in the Euro heart of the acute coronary syndrome survey and Canadian ACS registry $[13,14$, $76,77]$. The rates of diabetes are ranged from $23.3 \%$ to $25.1 \%$ in the Euro heart survey, Canadian ACS registry, and the Global Registry of Acute Cardiac Events (GRACE) [76, 77], while the prevalence of diabetes is much higher among the ACS patients in the Gulf States especially in Saudi Arabia $(56 \%)[13,14]$. One possible explanation for this high rate of diabetes could be due the high prevalence of obesity and physical inactivity in the GCC region, especially in Saudi Arabia. Furthermore, the mean age of presentation in the SPACE and Gulf RACE cohort is about ten years younger than that reported in the Euro heart survey and the GRACE cohort $[13,14,78,79]$. This might be due to the high rates of uncontrolled risk factors in the Gulf region as well as the high percentage of younger populations in these countries.

The crude annual incidence of stroke in the Gulf countries was generally lower than the reported incidence in some Arabic countries, for example, Libya $(63 / 100,000)$ [80] and Northern Palestine $(51.4 / 100,000)$ [81]. The incidence is even much lower than that which is observed in some of the developed countries such as Scotland $(280 / 100,000)$ [82] and the East Coast of Australia $(206 / 100,000)$ [83]. The low rates of strokes in the GCC countries could be explained by the relatively younger age of patients in these countries. Further, the majority of stroke studies in the region had no record on the number of patients who died before reaching hospital, thus underestimating the actual incidence rate.

Several studies in the Gulf States have reported a high incidence of stroke at a younger age. Of the stroke patients, $9.8 \%$ to $25 \%$ were less than 45 years old $[17,23,25]$. The higher proportion of undiagnosed hypertension and diabetes might be a reason for younger stroke patients. One study in Saudi Arabia showed that only half of the hypertensive stroke patients were actually on medication [17]. Further, lack of awareness about stroke in the Gulf countries might have led to an increase in the incidence of strokes as well as the rates of associated risk factors [84].

When looking at the burden of risk factors among healthy subjects in the GCC region, the prevalence of obesity in adult females is one of the highest amongst females worldwide. This review found that almost half of the females in Kuwait and Bahrain and around 35\% of females in Saudi Arabia, the UAE, and Qatar were obese. The overall prevalence of overweight and obesity in the GCC is higher than that which was reported in other Middle Eastern countries such as Lebanon and Turkey $[85,86]$. The prevalence was even higher than in many developed countries such as the USA and in developing countries such as India $[87,88]$. The food customs in the Gulf region, such as weddings and religious events, might be an important contributory factor for such a high rate of obesity as they serve food that is rich in fat, usually "Kabsa," which includes meat (from sheep or small camel) 
with rice. Even socialising with friends and family is usually around eating meals and snacks.

Likewise, more than half of the GCC population are physically inactive, with only a small proportion of people being active on a regular basis. Furthermore, the rate of inactivity appeared to be remarkably higher in Saudi Arabia than in other Gulf countries. The reviewed studies also indicated that males are more likely to be physically active than females, a finding similar to that was reported in Turkey and Pakistan [47]. The unique social, cultural, and environmental factors of the GCC states, such as hot climate, lack of outdoor facilities, the limited number of health clubs, high cost of attending such clubs especially for females, high level of employment of domestic helpers, and the high dependency on automobiles are blamed on the increased levels of physical inactivity in both genders but more noticeably in females. Also, females have more social barriers that make it difficult for them to exercise outside the home without a family member $[5,89]$.

In the Gulf region, males start smoking cigarettes at an early age (before 18 years), while females generally start after 30 s. Cigarette smoking by younger and unmarried females is viewed as culturally unacceptable and can potentially destroy their reputation. However, the case is different when smoking sheesha (water-pipe) as Arabic societies in general accept sheesha smoking by females irrespective of their age and/or social status.

Hypertension and diabetes are the two major risk factors associated with CHD and stroke patients in all studies in the Gulf region; this might be related to the high rates of undiagnosed hypertensive and diabetic patients within the region. In Saudi Arabia, about $70 \%$ of the hypertensive people were unaware of their disease [35]. A similar situation was reported in Oman, the UAE, and Bahrain [44, 65, 69]. Likewise, a large number of diabetic subjects in Saudi Arabia $(28 \%)$ and the UAE $(41 \%)$ were unaware of their disease $[29,45]$. The high rates of uncontrolled diseases such as hypertension and diabetes could be a reason for the relatively young age of $\mathrm{CHD}$ and stroke patients in the Gulf region.

The prevalence of dyslipidaemia in general is high in the GCC countries. The available national surveys indicated that half the Saudi population have high level of total cholesterol and almost half of the males and one-third of Saudi females have high level of hypertriglyceridemia [37]. The rates of HC in Saudi Arabia are similar to that reported in USA (53.2\%) [90]. Dyslipidaemia is a major risk factor for CHD and plays a central role in the development of atherosclerosis. The high rates of dyslipidaemia in the GCC countries may be due to the high prevalence of physical inactivity, obesity, and diabetes among the Gulf populations. Also, as mentioned before, food customs and the consumption of high fatty foods might be contributing factors.

This review has a number of limitations. First, there was a lack of recent nationally representative reports in the GCC countries, and thus it is difficult to compare the data between GCC countries. Second, there was significant heterogeneity between studies with respect to definitions of the risk factors, design, and population characteristics. Third, only a few studies reported stroke incidence and the majority of them were hospital-based studies with an absence of data on Oman and the UAE. Fourth, there were only a few studies focusing on hypertension, dyslipidaemia, and physical activity. Moreover, the number of included studies relating to the prevalence of risk factors in Qatar and Bahrain were also relatively low. However, the strength of this review was that the literature search was conducted on multiple databases including personal contact of the authors to capture all relevant documents.

\section{Conclusion}

The present review revealed lower incidence of strokes in the GCC countries than in developed countries and that those affected were younger than in some developing and developed countries. Although there was lack of nationally representative data on the prevalence of CHD in the region, high prevalence of key risk factors was observed. Further, the patterns of risk factors were very similar between the Gulf countries; this may be due to the similarity in culture, religion, cuisine, lifestyle, and environmental factors between these countries. With the rapid urbanization in the Gulf region and the relatively young population, the prevalence of CHD and strokes is expected to increase in the next few decades, which in turn will raise the rate of CVD mortality and morbidity in the region. Well-designed populationbased nationally representative surveys focusing on CVD and its associated risk factors are crucial in the Gulf States. Furthermore, there is a need to increase the awareness of the high prevalence of CVD and associated risk factors among the public along with education programs on nutrition and healthier lifestyles including increase in physical activity levels in both men and women. In addition, there is also a need for preventative strategies, especially for type 2 diabetes, to be used in the region and the cooperation in management strategies, especially in obesity and diabetes is also crucial across the region. Moreover, addressing some of the cultural and social barriers that were mentioned previously is also important for reducing the risk of CVD and related risk factors among the GCC population.

\section{Conflict of Interests}

The authors declare that they have no competing interests.

\section{Authors' Contribution}

Najlaa Aljefree designed the concept of study and prepared the paper draft. Faruk Ahmed has provided guidance on the study design and critically reviewed the paper. All authors read and approved the final paper.

\section{Acknowledgments}

Mrs. Najlaa Aljefree is supported by a scholarship from King Abdul Aziz University for Nutrition and Dietetics. The King Abdul Aziz University had no role in the design, analysis, or writing of this paper. 


\section{References}

[1] S. Mendis, P. Puska, and B. Norrving, Global Atlas on Cardiovascular Disease Prevention and Control, World Health Organization, 2011.

[2] M. J. O’Donnell, X. Denis, L. Liu et al., "Risk factors for ischaemic and intracerebral haemorrhagic stroke in 22 countries (the INTERSTROKE Study): a case-control study," The Lancet, vol. 376, no. 9735, pp. 112-123, 2010.

[3] S. Yusuf, S. Hawken, S. Ônpuu et al., "Effect of potentially modifiable risk factors associated with myocardial infarction in 52 countries (the INTERHEART study): case-control study," The Lancet, vol. 364, no. 9438, pp. 937-952, 2004.

[4] The Cooperation Council for the Arab States of the Gulf, http:// www.gcc-sg.org/.

[5] R. M. Mabry, M. M. Reeves, E. G. Eakin, and N. Owen, "Evidence of physical activity participation among men and women in the countries of the gulf cooperation council: a review," Obesity Reviews, vol. 11, no. 6, pp. 457-464, 2010.

[6] C. M. Lawes, S. V. Hoorn, and A. Rodgers, "Global burden of blood-pressure-related disease, 2001," The Lancet, vol. 371, no. 9623, pp. 1513-1518, 2008.

[7] WHO, Noncommunicable Diseases Country Profiles 2011, World Health Organization, Geneva, Switzerland, 2011.

[8] B. Motlagh, M. O’Donnell, and S. Yusuf, "Prevalence of cardiovascular risk factors in the middle east: a systematic review," European Journal of Cardiovascular Prevention and Rehabilitation, vol. 16, no. 3, pp. 268-280, 2009.

[9] N. M. Shara, "Cardiovascular disease in Middle Eastern women,' 'Nutrition, Metabolism and Cardiovascular Diseases, vol. 20, no. 6, pp. 412-418, 2010.

[10] Systematic Reviews: CRD's Guidance for Undertaking Reviews in Health Care, University of York, Centre for Reviews and Dissemination, York, UK, 2009.

[11] M. M. Al-Nozha, M. R. Arafah, Y. Y. Al-Mazrou et al., "Coronary artery disease in Saudia Arabia," Saudi Medical Journal, vol. 25, no. 9, pp. 1165-1171, 2004.

[12] A. El-Menyar, M. Zubaid, W. Rashed et al., "Comparison of men and women with acute coronary syndrome in six Middle Eastern countries," The American Journal of Cardiology, vol. 104, no. 8, pp. 1018-1022, 2009.

[13] A. El-Menyar, M. Zubaid, A. Shehab et al., "Prevalence and impact of cardiovascular risk factors among patients presenting with acute coronary syndrome in the Middle East," Clinical Cardiology, vol. 34, no. 1, pp. 51-58, 2011.

[14] K. F. AlHabib, A. Hersi, H. AlFaleh et al., "The Saudi Project for Assessment of Coronary Events (SPACE) registry: design and results of a phase I pilot study," Canadian Journal of Cardiology, vol. 25, no. 7, pp. e255-e258, 2009.

[15] S. Al Rajeh, A. Awada, G. Niazi, and E. Larbi, "Stroke in a Saudi Arabian National Guard community: analysis of 500 consecutive cases from a population-based hospital," Stroke, vol. 24, no. 11, pp. 1635-1639, 1993.

[16] S. Al Rajeh, O. Bademosi, H. Ismail et al., "A community survey of neurological disorders in Saudi Arabia: the Thugbah study," Neuroepidemiology, vol. 12, no. 3, pp. 164-178, 1993.

[17] S. Al-Rajeh, E. B. Larbi, O. Bademosi et al., "Stroke register: experience from the eastern province of Saudi Arabia," Cerebrovascular Diseases, vol. 8, no. 2, pp. 86-89, 1998.

[18] F. A. Qari, "Profile of stroke in a teaching university hospital in the western region," Saudi Medical Journal, vol. 21, no. 11, pp. 1030-1033, 2000.
[19] A. Al-Jishi and P. Mohan, "Profile of stroke in Bahrain," Neurosciences, vol. 5, no. 1, pp. 30-34, 2000.

[20] N. U. A. M. A. Abdul-Ghaffar, M. R. El-Sonbaty, M. S. ElDin Abdul-Baky, A. A. Marafie, and A. M. Al-Said, "Stroke in Kuwait: a three-year prospective study," Neuroepidemiology, vol. 16, no. 1, pp. 40-47, 1997.

[21] S. Al-Shammri, Z. Shahid, A. Ghali et al., "Risk factors, subtypes and outcome of ischaemic stroke in Kuwait-a hospital-based study," Medical Principles and Practice, vol. 12, no. 4, pp. 218223, 2003.

[22] A. Ashkanani, K. A. Hassan, and S. Lamdhade, "Risk factors of stroke patients admitted to a general hospital in Kuwait," International Journal of Neuroscience, vol. 123, no. 2, pp. 89-92, 2013.

[23] N. Akhtar, S. I. Kamran, D. Deleu et al., "Ischaemic posterior circulation stroke in State of Qatar," European Journal of Neurology, vol. 16, no. 9, pp. 1004-1009, 2009.

[24] D. Deleu, A. A. Hamad, S. Kamram, A. El Siddig, H. Al Hail, and S. M. K. Hamdy, "Ethnic variations in risk factor profile, pattern and recurrence of non-cardioembolic ischemic stroke," Archives of Medical Research, vol. 37, no. 5, pp. 655-662, 2006.

[25] A. Hamad, T. E. O. Sokrab, S. Momeni, B. Mesraoua, and A. Lingren, "Stroke in Qatar: a one-year, hospital-based study," Journal of Stroke and Cerebrovascular Diseases, vol. 10, no. 5, pp. 236-241, 2001.

[26] D. Deleu, J. Inshasi, N. Akhtar et al., "Risk factors, management and outcome of subtypes of ischemic stroke: a stroke registry from the Arabian Gulf," Journal of the Neurological Sciences, vol. 300, no. 1-2, pp. 142-147, 2011.

[27] B. A. Abalkhail, S. Shawky, T. M. Ghabrah, and W. A. Milaat, "Hypercholesterolemia and 5-year risk of development of coronary heart disease among university and school workers in Jeddah, Saudi Arabia," Preventive Medicine, vol. 31, no. 4, pp. 390395, 2000.

[28] A. A. Al-Nuaim, E. A. Bamgboye, K. A. Al-Rubeaan, and Y. AlMazrou, "Overweight and obesity in Saudi Arabian adult population, role of sociodemographic variables," Journal of Community Health, vol. 22, no. 3, pp. 211-223, 1997.

[29] M. M. Al-Nozha, M. A. Al-Maatouq, Y. Y. Al-Mazrou et al., "Diabetes mellitus in Saudi Arabia," Saudi Medical Journal, vol. 25, no. 11, pp. 1603-1610, 2004.

[30] T. J. Hashim, "Smoking habits of students in College of Applied Medical Science, Saudi Arabia," Saudi Medical Journal, vol. 21, no. 1, pp. 76-80, 2000.

[31] A. Rahman Al-Nuaim, "High prevalence of metabolic risk factors for cardiovascular diseases among Saudi population, aged 30-64 years," International Journal of Cardiology, vol. 62, no. 3, pp. 227-235, 1997.

[32] M. M. Al-Nozha, Y. Y. Al-Mazrou, M. A. Al-Maatouq et al., "Obesity in Saudi Arabia," Saudi Medical Journal, vol. 26, no. 5, pp. 824-829, 2005.

[33] K. A. Kalantan, A. G. Mohamed, A. A. Al-Taweel, and H. M. Abdul Ghani, "Hypertension among attendants of primary health care centers in Al-Qassim region, Saudi Arabia," Saudi Medical Journal, vol. 22, no. 11, pp. 960-963, 2001.

[34] S. A. Al-Refaee and H. M. Al-Hazzaa, "Physical activity profile of adult males in Riyadh City," Saudi Medical Journal, vol. 22, no. 9, pp. 784-789, 2001.

[35] M. M. Al-Nozha, M. Abdullah, M. R. Arafah et al., "Hypertension in Saudi Arabia," Saudi Medical Journal, vol. 28, no. 1, pp. 77-84, 2007. 
[36] M. M. Al-Nozha, H. M. Al-Hazzaa, M. R. Arafah et al., "Prevalence of physical activity and inactivity among Saudis aged 30-70 years: a population-based cross-sectional study," Saudi Medical Journal, vol. 28, no. 4, pp. 559-568, 2007.

[37] M. M. Al-Nozha, M. R. Arafah, M. A. Al-Maatouq et al., "Hyperlipidemia in Saudi Arabia," Saudi Medical Journal, vol. 29, no. 2, pp. 282-287, 2008.

[38] N. S. Al-Haddad, T. A. Al-Habeeb, M. H. Abdelgadir, Y. S. AlGhamdy, and N. A. Qureshi, "Smoking patterns among primary health care attendees, Al-Qassim region, Saudi Arabia," Eastern Mediterranean Health Journal, vol. 9, no. 5-6, pp. 911-922, 2003.

[39] N. A. Al-Baghli, A. J. Al-Ghamdi, K. A. Al-Turki, A. G. ElZubaier, M. Al-Ameer, and F. A. Al-Baghli, "Overweight and obesity in the eastern province of Saudi Arabia," Saudi Medical Journal, vol. 29, no. 9, pp. 1319-1325, 2008.

[40] I. A. Hakim, M. A. Alsaif, A. Aloud et al., "Black tea consumption and serum lipid profiles in Saudi women: a cross-sectional study in Saudi Arabia," Nutrition Research, vol. 23, no. 11, pp. 1515-1526, 2003.

[41] F. Y. Abdel-Megeid, H. M. Abdelkarem, and A. M. El-Fetouh, "Unhealthy nutritional habits in university students are a risk factor for cardiovascular diseases," Saudi Medical Journal, vol. 32, no. 6, pp. 621-627, 2011.

[42] F. Midhet, A. R. Al Mohaimeed, and F. Sharaf, "Dietary practices, physical activity and health education in qassim region of Saudi Arabia," International Journal Of Health Sciences, vol. 4, no. 1, pp. 3-10, 2010.

[43] C. Hajat, O. Harrison, and Z. Al Siksek, "Weqaya: A populationwide cardiovascular screening program in Abu Dhabi, United Arab Emirates," The American Journal of Public Health, vol. 102, no. 5, pp. 909-914, 2012.

[44] Y. El-Shahat, S. Z. Bakir, N. Farjou et al., "Hypertension in UAE citizens-preliminary results of a prospective study," Saudi Journal of Kidney Diseases and Transplantation, vol. 10, no. 3, pp. 376-381, 1999.

[45] M. Malik, A. Bakir, B. Abi Saab, G. Roglic, and H. King, "Glucose intolerance and associated factors in the multi-ethnic population of the United Arab Emirates: results of a national survey," Diabetes Research and Clinical Practice, vol. 69, no. 2, pp. 188-195, 2005.

[46] A. O. Carter, H. F. Saadi, R. L. Reed, and E. V. Dunn, "Assessment of obesity, lifestyle, and reproductive health needs of female citizens of Al Ain, United Arab Emirates," Journal of Health, Population and Nutrition, vol. 22, no. 1, pp. 75-83, 2004.

[47] R. Guthold, T. Ono, K. L. Strong, S. Chatterji, and A. Morabia, "Worldwide variability in physical inactivity: a 51-Country Survey," The American Journal of Preventive Medicine, vol. 34, no. 6, pp. 486-494, 2008.

[48] T. Al-Sarraj, H. Saadi, J. S. Volek, and M. L. Fernandez, "Metabolic syndrome prevalence, dietary intake, and cardiovascular risk profile among overweight and obese adults 18-50 years old from the united arab emirates," Metabolic Syndrome and Related Disorders, vol. 8, no. 1, pp. 39-46, 2010.

[49] A. Kerkadi, "Evaluation of nutritional status of united arab emirates university female students," Emirates Journal of Food and Agriculture, vol. 15, no. 2, pp. 42-50, 2003.

[50] A. O. Musaiger and N. M. Abuirmeileh, "Food consumption patterns of adults in the United Arab Emirates," The Journal of The Royal Society for the Promotion of Health, vol. 118, no. 3, pp. 146-150, 1998.
[51] N. Abdella, M. Al Arouj, A. Al Nakhi, A. Al Assoussi, and M. Moussa, "Non-insulin-dependent diabetes in Kuwait: prevalence rates and associated risk factors," Diabetes Research and Clinical Practice, vol. 42, no. 3, pp. 187-196, 1998.

[52] A. Memon, P. M. Moody, T. N. Sugathan et al., "Epidemiology of smoking among Kuwaiti adults: prevalence, characteristics, and attitudes," Bulletin of the World Health Organization, vol. 78, no. 11, pp. 1306-1315, 2000.

[53] F. Ahmed, C. Waslien, M. Al-Sumaie, and P. Prakash, “Trends and risk factors of hypercholesterolemia among Kuwaiti adults: National Nutrition Surveillance Data from 1998 to 2009," Nutrition, vol. 28, no. 9, pp. 917-923, 2012.

[54] I. Al Rashdan and Y. Al Nesef, "Prevalence of overweight, obesity, and metabolic syndrome among adult Kuwaitis: results from community-based national survey," Angiology, vol. 61, no. 1, pp. 42-48, 2010.

[55] F. Ahmed, C. Waslien, M. A. Al-Sumaie, and P. Prakash, "Secular trends and risk factors of overweight and obesity among Kuwaiti adults: National Nutrition Surveillance System data from 1998 to 2009," Public Health Nutrition, vol. 15, no. 11, pp. 2124-2130, 2012.

[56] F. Ahmed, C. Waslien, M. A. Al-Sumaie, P. Prakash, and A. Allafi, "Trends and risk factors of hyperglycemia and diabetes among Kuwaiti adults: National Nutrition Surveillance Data from 2002 to 2009," BMC Public Health, vol. 13, no. 1, article 103, 2013.

[57] H. R. Mohammed, I. M. Newman, and R. Tayeh, "Sheesha smoking among a sample of future teachers in Kuwait," Kuwait Medical Journal, vol. 38, no. 2, article 107, 2006.

[58] A. Bener, J. Al-Suwaidi, K. Al-Jaber, S. Al-Marri, and I. E. A. Elbagi, "Epidemiology of hypertension and its associated risk factors in the Qatari population," Journal of Human Hypertension, vol. 18, no. 7, pp. 529-530, 2004.

[59] A. Bener, M. Zirie, I. M. Janahi, A. O. A. A. Al-Hamaq, M. Musallam, and N. J. Wareham, "Prevalence of diagnosed and undiagnosed diabetes mellitus and its risk factors in a population-based study of Qatar," Diabetes Research and Clinical Practice, vol. 84, no. 1, pp. 99-106, 2009.

[60] A. O. Musaiger, F. A. Al-Khalaf, and N. E. Shahbeek, "Risk factors for cardiovascular disease among women attending health centers in Qatar," Emirates Journal of Food and Agriculture, vol. 6, no. 1, pp. 188-200, 1994.

[61] A. A. Al Riyami and M. Afifi, "Smoking in Oman: prevalence and characteristics of smokers," Eastern Mediterranean Health Journal, vol. 10, no. 4-5, pp. 600-609, 2004.

[62] S. Al-Moosa, S. Allin, N. Jemiai, J. Al-Lawati, and E. Mossialos, "Diabetes and urbanization in the Omani population: an analysis of national survey data," Population Health Metrics, vol. 4, article 5, 2006.

[63] J. A. Al-Lawati and P. J. Jousilahti, "Prevalence and 10-year secular trend of obesity in Oman," Saudi Medical Journal, vol. 25, no. 3, pp. 346-351, 2004.

[64] J. A. Al-Lawati and P. Jousilahti, "Body mass index, waist circumference and waist-to-hip ratio cut-off points for categorisation of obesity among Omani Arabs," Public Health Nutrition, vol. 11, no. 1, pp. 102-108, 2008.

[65] A. Al Riyami, M. A. Abd Elaty, M. Morsi, H. Al Kharusi, W. Al Shukaily, and S. Jaju, "Oman World Health Survey: part 1methodology, sociodemographic profile and epidemiology of non-communicable diseases in Oman," Oman Medical Journal, vol. 27, no. 5, pp. 425-443, 2012. 
[66] F. Al-Mahroos and K. Al-Roomi, "Obesity among adult Bahraini population: impact of physical activity and educational level," Annals of Saudi Medicine, vol. 21, no. 3-4, pp. 183-187, 2001.

[67] A. O. Musaiger and M. A. Al-Mannai, "Social and lifestyle factors associated with diabetes in the adult Bahraini population," Journal of Biosocial Science, vol. 34, no. 2, pp. 277-281, 2002.

[68] A. O. Musaiger and M. A. Al-Mannai, "Weight, height, body mass index and prevalence of obesity among the adult population in Bahrain," Annals of Human Biology, vol. 28, no. 3, pp. 346-350, 2001.

[69] F. Al-Mahroos, K. Al-Roomi, and P. M. McKeigue, "Relation of high blood pressure to glucose intolerance, plasma lipids and educational status in an Arabian Gulf population," International Journal of Epidemiology, vol. 29, no. 1, pp. 71-76, 2000.

[70] F. Al-Mahroos and P. M. Mckeigue, "High prevalence of diabetes in bahrainis: associations with ethnicity and raised plasma cholesterol," Diabetes Care, vol. 21, no. 6, pp. 936-942, 1998.

[71] R. R. Hamadeh and A. O. Musaiger, "Lifestyle patterns in smokers and non-smokers in the state of Bahrain," Nicotine \& Tobacco Research, vol. 2, no. 1, pp. 65-69, 2000.

[72] F. I. Al Zurba and A. Al Garf, "Prevalence of diabetes mellitus among Bahrainis attending primary health care centres," Eastern Mediterranean Health Journal, vol. 2, no. 2, pp. 274-282, 1996.

[73] W. Almahmeed, M. S. Arnaout, R. Chettaoui et al., "Coronary artery disease in Africa and the Middle East," Therapeutics and Clinical Risk Management, vol. 8, pp. 65-72, 2012.

[74] S. S. Anand, S. Yusuf, V. Vuksan et al., "Differences in risk factors, atherosclerosis, and cardiovascular disease between ethnic groups in Canada: the Study of Health Assessment and Risk in Ethnic groups (SHARE)," The Lancet, vol. 356, no. 9226, pp. 279-284, 2000.

[75] R. Gupta, P. Joshi, V. Mohan, K. S. Reddy, and S. Yusuf, "Epidemiology and causation of coronary heart disease and stroke in India," Heart, vol. 94, no. 1, pp. 16-26, 2008.

[76] A. T. Yan, P. Jong, R. T. Yan et al., "Clinical trial-derived risk model may not generalize to real-world patients with acute coronary syndrome," American Heart Journal, vol. 148, no. 6, pp. 1020-1027, 2004.

[77] A. Rosengren, L. Wallentin, M. Simoons et al., "Cardiovascular risk factors and clinical presentation in acute coronary syndromes," Heart, vol. 91, no. 9, pp. 1141-1147, 2005.

[78] D. Hasdai, S. Behar, L. Wallentin et al., "A prospective survey of the characteristics, treatments and outcomes of patients with acute coronary syndromes in Europe and the Mediterranean basin: the Euro Heart Survey of Acute Coronary Syndromes (Euro Heart Survey ACS)," European Heart Journal, vol. 23, no. 15, pp. 1190-1201, 2002.

[79] K. A. A. Fox, S. G. Goodman, F. A. Anderson Jr. et al., "From guidelines to clinical practice: the impact of hospital and geographical characteristics on temporal trends in the management of acute coronary syndromes: the Global Registry of Acute Coronary Events (GRACE)," European Heart Journal, vol. 24, no. 15, pp. 1414-1424, 2003.

[80] P. P. Ashok, K. Radhakrishnan, R. Sridharan, and M. A. ElMangoush, "Incidence and pattern of cerebrovascular diseases in Benghazi, Libya," Journal of Neurology Neurosurgery and Psychiatry, vol. 49, no. 5, pp. 519-523, 1986.

[81] W. M. Sweileh, A. F. Sawalha, S. M. Al-Aqad, S. H. Zyoud, and S. W. Al-Jabi, "The epidemiology of stroke in northern palestine: a 1-year, hospital-based study," Journal of Stroke and Cerebrovascular Diseases, vol. 17, no. 6, pp. 406-411, 2008.

[82] P. D. Syme, A. W. Byrne, R. Chen, R. Devenny, and J. F. Forbes, "Community-based stroke incidence in a Scottish population: the Scottish borders stroke study," Stroke, vol. 36, no. 9, pp. 1837$1843,2005$.

[83] A. G. Thrift, H. M. Dewey, R. A. L. Macdonell, J. J. McNeil, and G. A. Donnan, "Stroke incidence on the east coast of Australia: the North East Melbourne Stroke Incidence Study (NEMESIS)," Stroke, vol. 31, no. 9, pp. 2087-2092, 2000.

[84] S. Kamran, A. B. Bener, D. Deleu et al., "The level of awareness of stroke risk factors and symptoms in the Gulf Cooperation Council countries: Gulf Cooperation Council stroke awareness study," Neuroepidemiology, vol. 29, no. 3-4, pp. 235-242, 2008.

[85] A. M. Sibai, N. Hwalla, N. Adra, and B. Rahal, "Prevalence and covariates of obesity in Lebanon: findings from the first epidemiological study," Obesity Research, vol. 11, no. 11, pp. 1353-1361, 2003.

[86] C. Erem, C. Arslan, A. Hacihasanoglu et al., "Prevalence of obesity and associated risk factors in a Turkish population (Trabzon City, Turkey)," Obesity Research, vol. 12, no. 7, pp. 1117$1127,2004$.

[87] C. L. Ogden, M. D. Carroll, L. R. Curtin, M. A. McDowell, C. J. Tabak, and K. M. Flegal, "Prevalence of overweight and obesity in the United States, 1999-2004," The Journal of the American Medical Association, vol. 295, no. 13, pp. 1549-1555, 2006.

[88] A. Misra, R. M. Pandey, J. R. Devi, R. Sharma, N. K. Vikram, and N. Khanna, "High prevalence of diabetes, obesity and dyslipidaemia in urban slum population in northern India," International Journal of Obesity, vol. 25, no. 11, pp. 1722-1729, 2001.

[89] A. M. Sibai, L. Nasreddine, A. H. Mokdad, N. Adra, M. Tabet, and N. Hwalla, "Nutrition transition and cardiovascular disease risk factors in middle East and North Africa countries: reviewing the evidence," Annals of Nutrition \& Metabolism, vol. 57, no. 3-4, pp. 193-203, 2011.

[90] E. S. Ford, C. Li, W. S. Pearson, G. Zhao, and A. H. Mokdad, "Trends in hypercholesterolemia, treatment and control among United States adults," International Journal of Cardiology, vol. 140, no. 2, pp. 226-235, 2010. 


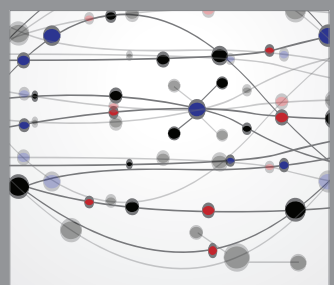

The Scientific World Journal
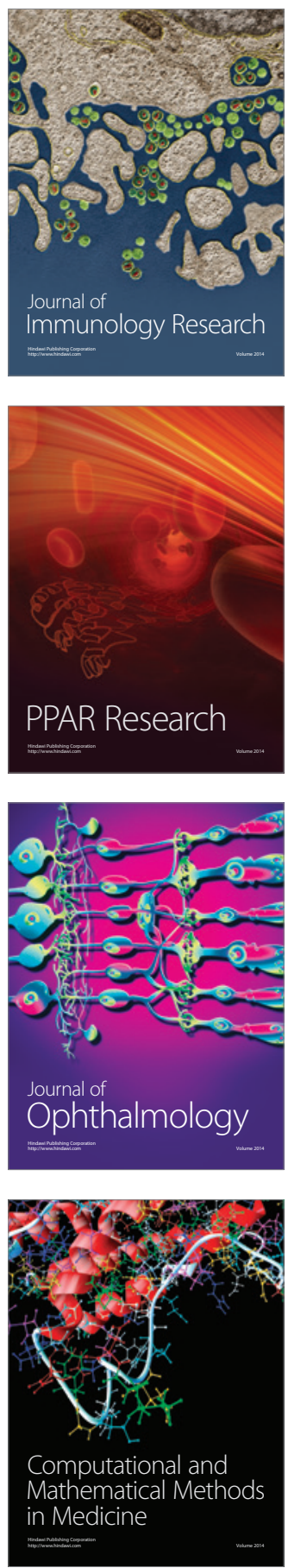

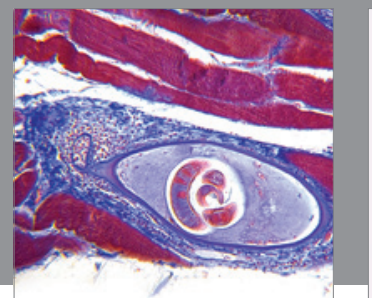

Gastroenterology

Research and Practice
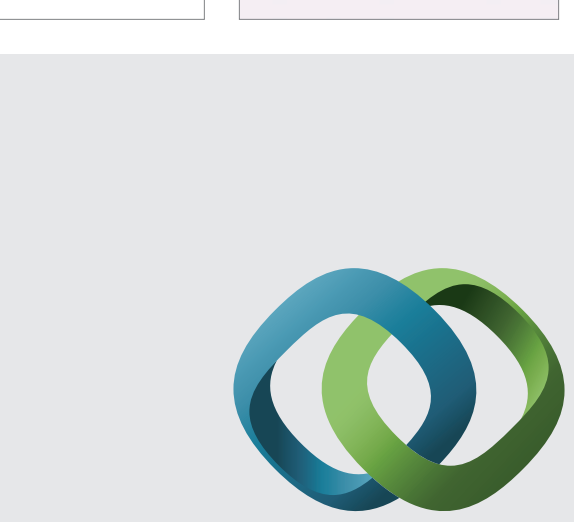

\section{Hindawi}

Submit your manuscripts at

http://www.hindawi.com
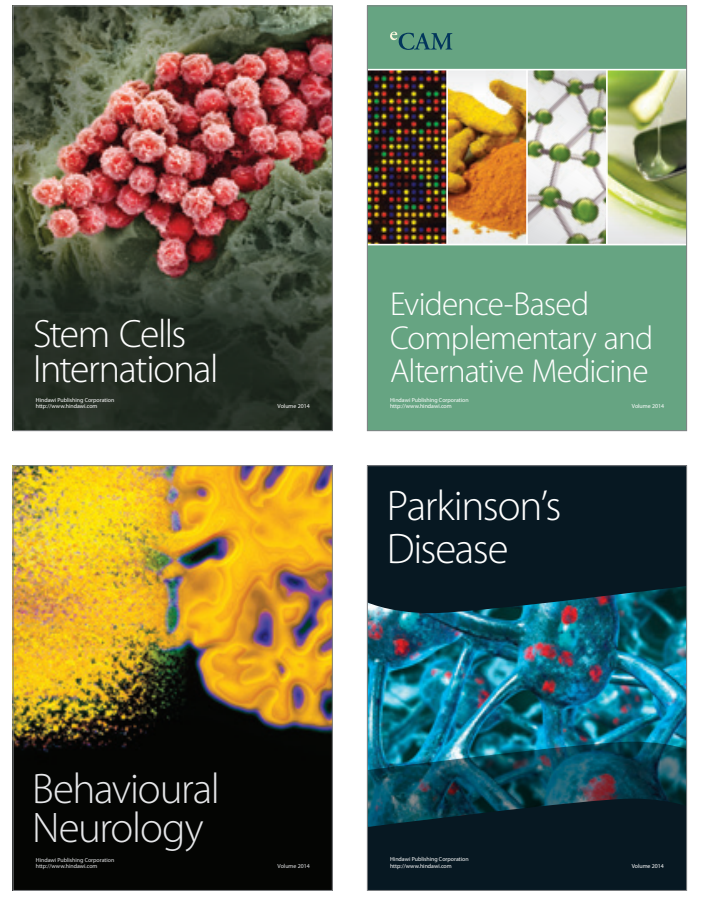
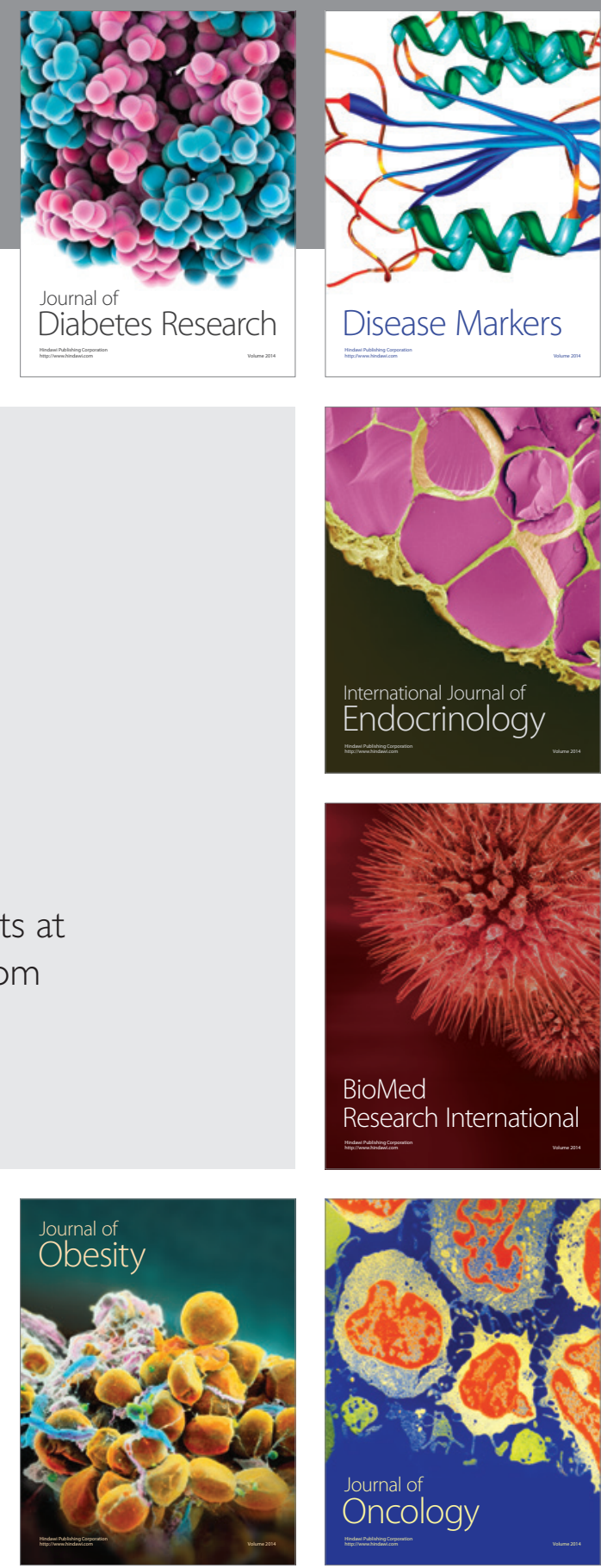

Disease Markers
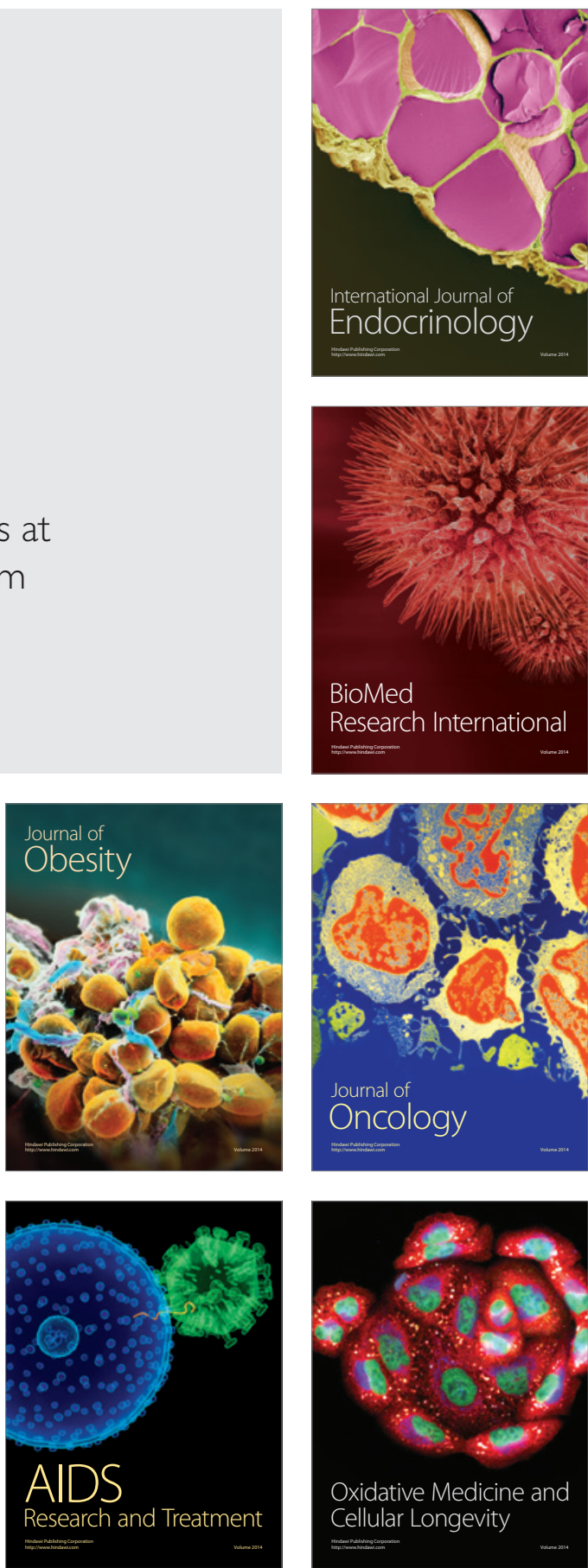